\title{
Trademark Squatters: Theory and Evidence from Chile*
}

\author{
Carsten Fink $^{a \dagger} \quad$ Christian Helmers ${ }^{b} \quad$ Carlos Ponce $^{c}$ \\ ${ }^{a}$ World Intellectual Property Organization (WIPO) \\ ${ }^{b}$ Santa Clara University \\ ${ }^{c}$ Universidad Alberto Hurtado
}

September 26, 2014

\begin{abstract}
This paper explores the phenomenon of "trademark squatting" - a situation in which someone other than the original brand owner obtains a trademark on a brand. We develop a model that shows how squatting results from market uncertainty that leads brand owners to rationally forgo registering trademarks, creating opportunities for squatting. We create an algorithm to identify squatters in the Chilean trademark register and show empirically that squatting is a persistent and systematic phenomenon. Using data on trademark oppositions, we show that squatting leads brand owners that have been exposed to squatting to 'over-protect' their brands by registering disproportionately many trademarks and covering classes other than those directly related to their products and services. Trademark squatting, therefore, creates a strategic, albeit excessive, response by brand owners which inflates trademark filings.
\end{abstract}

KEYWORDS: Trademark, squatter, strategic behavior, Chile.

JEL Classification: D22, M30, K11, O34

\footnotetext{
${ }^{*}$ We thank various law firms in Chile for generously sharing their experiences and opinions about trademark squatting. Bronwyn Hall, Keith Maskus, experts from the Instituto Nacional de Propiedad Inudstrial (INAPI) and the Dirección General de Relaciones Económicas Internacionales, participants at the Empirical Studies of Trademark Data workshop at Oxford University in 2012 and the USPTO in 2013, the European Policy for Intellectual Property Conference 2013 in Paris, MEIDE 2013, and workshops at WIPO and INAPI offered valuable comments on draft versions of this study. The authors are particularly grateful to Maria-José Abud for her excellent research assistance and to Aisen Etcheverry and Catalina Olivos Besserer for their generous support of this research. The views expressed in this paper are those of the authors and do not reflect those of WIPO or INAPI.

${ }^{\dagger}$ Corresponding author: carsten.fink@wipo.int
} 


\section{Introduction}

Trademarks are the most popular form of registered intellectual property not only in advanced economies, but especially in low- and middle-income economies (WIPO, 2013). According to WIPO (2013), there were an estimated total of 6.58 million trademark applications worldwide in 2012 11 Especially the large middle-income economies have experienced a dramatic increase in trademark filings over the past two decades. In China, for example, the annual number of trademark filings has exploded from a low level of around 57,000 in 1990 to over 1.5 million in 2012. Other fast-growing middle income economies such as Brazil, India, and Mexico also experienced substantial increases in trademark filings over the same period.

In recent years, popular media and specialized blogs have reported widely about a phenomenon called 'trademark squatting' that has accompanied the rapid surge in trademark filings around the world. This phenomenon describes a situation in which a company or individual registers a trademark that protects a good, service, or trading name of another company. This latter company has usually invested in brand recognition and built substantial goodwill in the product, service, or trading name, but has not registered a trademark. ${ }^{2}$ Squatters attempt to register such trademarks, in most cases, with the intention of extracting rents from the brand owners or other companies that rely on the brand, such as importers in case of foreign brands. A typical scenario is for a squatter to register the trademark of a foreign brand and wait until the foreign brand owner enters the local market. Once the brand owner has entered, the squatter may threaten to sue for trademark infringement. It may be possible for the brand owner to get the intellectual property office or a civil court to cancel the squatted trademark, but this is costly and may involve considerable delay and legal as well as commercial uncertainty. As a result, the brand owner may be willing to pay the squatter for abandoning, re-assigning, or licensing the trademark.

A case in point is the U.S. coffee shop chain Starbucks. When entering the Russian market in 2005, Starbucks faced the fact that its trademark was owned in Russia by an individual, Sergei Zuykov, who offered to re-assign the trademark for US\$600,000. Instead, Starbucks opted to invalidate Zuykov's trademark before court, which resulted in a protracted legal dispute substantially delaying Starbucks's entry into the Russian market. Other companies appear to have given in instead of risking litigation. In particular, Zuykov claims to have successfully squatted trademarks belonging to the German car manufacturer Audi. In an interview, he claimed to have sold five trademarks

\footnotetext{
${ }^{1}$ Technically, this figure refers to the number of classes specified in trademark applications worldwide.

${ }^{2}$ Trademarks are the intellectual property instrument that protects the exclusivity of brands. Trademarks are territorial rights, that is, they have to be registered in each jurisdiction in which protection is sought to take effect.
} 
to Audi in 2001 for the price of US\$25,000. Another example is that of Californian car maker Tesla. Tesla has faced a trademark squatter in China, which substantially delayed its entry into the Chinese market and upon entry, initially forced the company to market its cars only under the brand's English name because the squatter maintained ownership of the trademark on the Chinese name $?^{3}$

Although the main business model of squatters is to sell a squatted trademark to the corresponding brand owner, squatting may also be used for a number of other objectives. For example, squatting may be used to impede market entry ${ }^{4}$ Another strategy is for squatters to register a trademark and instead of pursuing the brand owner directly, squatters go after importers of products that rely on the brand. In the case of importers, squatters may be able to lever their power by obtaining a preliminary injunction to seize infringing products at the border $5^{5}$ Finally, trademark squatters may also use the trademark to market products or services while free-riding on the brand reputation. This may dilute the original brand and result in forgone sales if the squatter markets similar products under the brand name as the original brand owner.

At first, it may appear counterintuitive that an individual or company can register a trademark on the brand or trading name of a company that has created it and often invested substantial resources in building goodwill in the brand. However, trademark laws seek to achieve a balance between protecting the exclusive rights of brand owners while not unduly limiting the entry of new brands. In practice, the boundaries between bad-faith attempts at free-riding and good-faith entry of new brands are often not clearly drawn. In addition, there are important legal differences in the characteristics of trademark systems around the world that determine a squatter's ability to legally register someone else's brand. For example the absence of relative grounds examination paired with a first-to-file rule, such as in China, may favor squatting because trademarks are registered provided they satisfy basic formal criteria and there is no existing trademark in the desired class. Similarly, the absence of a use requirement - as in the case of Chile - may provide squatters with an increased ability to register trademarks speculatively $!^{6}$ Finally, trademark laws provide, in principle, special

\footnotetext{
${ }^{3}$ See Reuters and The New York Times

${ }^{4}$ For example in 2013, the Chilean Competition Commission - Fiscalía Nacional Económica - found that Chile's largest brewery (CCU) had registered a large number of its mostly foreign competitors' trademarks and enforced those squatted trademarks to effectively constrain competition.

${ }^{5}$ For example, in Chile, Telecomunicaciones Alemanas S.A. (TCA) sued a competing importer in both civil and criminal courts alleging the infringement of a trademark. The product concerned, however, was produced by a company in Germany and imported to Chile by both TCA and the competitor. The German company had not licensed its trademark to TCA. The competitor brought the issue before the competition authorities who ruled against TCA.

${ }^{6}$ The use requirement forces the owner of a trademark to prove use of the trademark in the specified classes at the time of registration and renewal. Systems that require proof of use - such as the U.S. - may provisionally allow showing merely an intent to use provided use is eventually demonstrated within a
} 
treatments to well-known trademarks, affording them protection even when they are not registered. However, what precisely qualifies as well-known is context-specific, which can be an important source of uncertainty and conflict 7 Whatever the legal regime, squatters appear to succeed in registering another company's trademarks in any jurisdiction. 8

Our objective is to assess the extent to which systematic trademark squatting exists and how it affects brand owners. We offer a simple theoretical model that shows under which circumstances squatting may be possible. That is, the model shows why a brand owner might rationally forego the registration of a trademark on his brand, which provides an opportunity for a squatter to appropriate the corresponding trademark. To investigate the existence of squatting beyond the anecdotal level, we develop a methodology to identify squatters empirically in the trademark register. Our methodology is based on characteristics of trademarks, filing behavior by squatters, oppositions filed by third parties, as well as rejections and cancellations by the trademark office. We apply this algorithm to the Chilean trademark register.

Chile offers an interesting setting to study squatting behavior. Trademarks are used pervasively in the Chilean economy; in total, there were almost 575,000 trademark filings over the 20-year period 1991-2010. In contrast to many other countries, the country's legal framework does not require that trademark holders actually use their registered trademarks. In addition, Chile is not part of the Madrid System for the International Registration of Marks. This may favor squatting on foreign brands as multinational companies cannot designate Chile in an international trademark registration under the Madrid system. In addition, applying for a trademark is relatively straightforward, in particular for residents familiar with the Chilean intellectual property system. By contrast, the process to have a trademark cancelled once it is registered takes about 2-3 years and costs around US $\$ 20,000-30,000$ according to practitioner estimates, where the bulk of the expenses is accounted for by fees for legal advice and representation. Anecdotal evidence for Chile suggests that negotiating with squatters leads to a much faster dispute resolution and the average price reportedly demanded by squatters of US $\$ 2,000$-US $\$ 10,000$ is substantially lower, illustrating how the squatter business model can work in practice.

However, assessing the impact of squatters empirically beyond the anecdotal level is more difficult. Transactions, and especially the corresponding prices, involved in

certain amount of time.

${ }^{7}$ See WIPO (2013), Chapter 2.

${ }^{8}$ For example, there is anecdotal evidence for trademark squatting in the UK which applies both a relative grounds examination and a use requirement - for example, the dispute around UK trademark 2463613 ("Juiced Up") which was registered by a squatter called Never Give Up ltd on a brand used by a company called Juiced Up ltd (see BBC|for details). 
(successful) squatting are largely unobserved except for the rare cases uncovered by the media for one reason or another or those that end in court. This makes it impossible to directly quantify the payoff reaped by squatters. Instead, we focus on the effect squatting has on brand owners. We analyze how brand owners react when a squatter attempts to squat a brand. Brand owners can respond to squatting in multiple ways. Clearly, one possible response is to purchase the squatted trademark from the squatter, which occurs behind closed doors and is hence unobservable to us. $9^{9}$ By contrast, we can observe disputes between squatters and brand owners. In particular, we use data from trademark oppositions to infer the impact of squatting on brand owners. We analyze the behavior of brand owners after they attempted to eliminate squatted trademarks through opposition. We test whether squatting leads to the preemptive filing of trademarks. Such preemptive filing behavior by brand owners can go beyond the registration of a company's core brands and turn into 'trademark fencing' which means a company trademarks multiple incarnations of a brand and even related terms which may not even be used to identify the company's products and services. Such fencing in particular also includes the registration of a trademark in classes unrelated to the product or service.

Our results show that our 'squatter algorithm' performs well at identifying squatters in the Chilean register. We find a substantial number of squatters and squatted trademarks - their share in total trademark filings is at least $1 \%$. Although this may seem moderate, it still involves around 300 applications on average per year between 1991 and 2010. Since squatters pick specific (often valuable foreign) brands, the number is in fact substantial. It bears noting that since our algorithm focuses on individuals or entities specializing in squatting, the number of squatted trademarks is a lower bound of the total squatting activity in Chile because brand owners that only have a few squatted trademarks in their portfolio (such as brewery CCU mentioned in footnote 4 above) are not classified as squatters by our algorithm. Focusing on those 'professional' squatters, we document interesting patterns in squatting behavior. Squatters predominantly file for trademarks in classes covering products rather than services. They cover a large range of different products; they are most active in clothes and luxury products, while - not surprisingly and reassuringly - absent in legal services. We also find that squatters are subject to relatively more opposition and cancellation proceedings. The fact that brand owners are more likely to take action against the registration of trademarks filed by squatters hints at the value of the squatted trademarks. Squatters also see their filings relatively more often rejected by

\footnotetext{
${ }^{9}$ There is no legal requirement in Chile for trademark re-assignments to be registered with the Chilean Intellectual Property office (INAPI). Nevertheless, we have some data on re-assignment of squatted trademarks to brand owners, which suggests that re-assignment does occur in practice.
} 
the trademark office. Yet, the evidence still indicates that on average $50 \%$ of filings by squatters are eventually registered. Taken together, these patterns strongly suggest systematic squatting behavior.

The analysis of the impact of squatting reveals that brand owners file preemptively for trademarks as a reaction to squatters. Our analysis of opposition data shows that brand owners react immediately after they notice that they have been targeted by a squatter by filing more trademarks. When we compare the post-opposition behavior of companies targeted by squatters to other companies opposing trademark filings by other non-squatting companies, we notice a significant increase in the number of trademark filings. When we compare the class distribution of trademark filings by brand owners before and after the first opposition of a squatted trademark, we find clear evidence for a broadening of the Nice class distribution 10 This indicates that brand owners engage in trademark fencing as an immediate reaction to squatting.

Trademarks have been seen as perhaps the most uncontroversial form of intellectual property in the economics literature as "there are strong economic advantages in allowing market participants to voluntarily identify themselves" (Boldrin and Levine, 2008: 8). Our analysis contributes to the literature by providing for the first time empirical evidence on trademark squatting beyond the anecdotal level - a phenomenon that obstructs this basic functioning of the trademark system. We offer a model that rationalizes brand owners' decisions to allow room for squatting. This highlights that squatting is not primarily the outcome of systematic mistakes by brand owners (management failure) or the trademark office (mistakes in the substantive examination). The model - a complete information dynamic game in the spirit of the real option literature (see Dixit and Pindyck, 1994) - differs from the existing related literature which has largely focused on brand stretching in the context of reputational games (Telser, 1980; Wernerfelt, 1988; Cabral, 2000). We propose a methodology that allows the identification of trademark squatters in any trademark register. In fact, our approach computes a squatter score for each applicant that can be interpreted as a measure for the likelihood that the applicant is a squatter. Recently, the Beijing No. 1 Intermediate People's Court in China suggested the use of a 'black list' of squatters to counter squatting behavior. A problem with this proposal is that it might be subject to substantial subjective judgment and hence manipulation 11 Our algorithm could assist trademark offices in creating such a list while minimizing the need for subjective judgments in the procedure. Our analysis also suggests that trademark squatting has real effects. Brand owners invest resources in eliminating squatter filings before they are granted and in seeking to cancel them post-grant. Brand-owners also respond

\footnotetext{
${ }^{10}$ Trademarks are classified into 45 classes according to the Nice Classification.

${ }^{11}$ For example, companies might accuse competitors of squatting to get them onto the black list.
} 
by filing preemptively which represents evidence for over-investment in intellectual property protection. Preemptive filings may well contribute to the rapid increases in trademark filings and to a potential cluttering of the register. This offers insights on strategic trademark filing behavior, an area that has received scant attention, especially in contrast to the strategic filing of patents.

The remainder of this paper is organized as follows. Section 2 develops a model that shows how brand owners may rationally leave space for squatters to appropriate their brands. Section 3 provides an overview of the Chilean trademark system. Section 4 describes the data used in this study. Section 5 summarizes the empirical approach used to identify squatters in the trademark register and shows the corresponding results. Section 6 assesses the impact of squatters on brand owners and section 7 discusses the corresponding results. Section 8 provides some concluding thoughts.

\section{The economics of trademark squatting}

This section presents a simple model that discusses the economics underlying squatting behavior. It shows how squatting can exist systematically and how this affects the optimal behavior of brand owners. The model also provides several theoretical predictions that help us identify squatters in the trademark register.

\subsection{The Basic Model}

We construct a model with two risk-neutral agents: a (foreign) brand owner, agent 1 , and a (resident) squatter, agent 2 . The framework we use to analyze squatting behavior is a multi-stage game with complete and perfect information. We distinguish two phases of our game: the application phase and the cancellation-negotiation phase.

\subsection{The Application Phase}

Each agent has two possible actions: file a trademark application or not in the country in which the squatter resides. Agents take their actions in the following order. At date 0 , it is the brand owner who takes his application decision. At date 1, if the brand owner has not registered the brand, the squatter decides whether to file an application or not. Finally, at date 2, if none of them have registered the brand yet, the brand owner has a last chance of doing so. This timing, as will become clear below, is the simplest possible to understand the economics of squatting behavior.

Filing an application is costly. Let $c_{i}$ be the application cost for agent $i=1,2$. The $\operatorname{cost} c_{i}$ captures not only filing fees but also, and more importantly, the costs of search- 
ing and hiring a suitable trademark agent, lawyers' honorarium, etc. Since this latter component of the cost is likely to be smaller for the local squatter ${ }^{12}$ we let $c_{1} \geq c_{2}>0$. The brand owner gets his application approved with certainty. A squatter, however, gets his application approved only with probability $\lambda \in(0,1)$. In other words, $1-\lambda$ measures how likely it is that the trademark office recognizes the brand as already existing or well-known.

At date 0 , there is uncertainty with respect to both the market potential of the brand and the presence of the squatter. We begin by discussing the uncertainty with respect to the market. The market potential - the state of the market or simply the state can be either good or bad. The agents believe that the state is good with probability $\mu \in(0,1)$. The profits that either the brand owner or the squatter obtains by registering the brand depend on the state. We assume, without any loss of generality, that when the state is bad profits are zero.

The profits that the brand owner realizes by registering the brand are equal to $h>0$ when the state is good. His benefit may come from different sources. For instance, he may either exploit the brand himself or he may establish franchises in the foreign country. The sources of rents for the squatter may also be diverse. He may either sell the trademark to the brand owner or enforce it vis-à-vis third parties that rely on the trademark, such as importers. We discuss these issues in more detail in the second phase of our game. Profits and costs are related as follows:

$$
\mu h>c_{1} .
$$

The assumption captures the idea that filing an application at date 0 is, in expected terms, profitable for the brand owner. Note however that if the state turns out to be bad, the brand owner will suffer a loss.

We now describe the uncertainty with respect to the presence of the squatter. We assume that the squatter will be available to play this game only with probability $\xi \in[0,1]$. We refer to $\xi$ as the participation probability. With this assumption we intend to capture in a simple way the ignorance that the brand owner might have concerning the existence and sophistication of the squatting activity. Of course, it might well be that $\xi=1$.

The uncertainty concerning the state of the market resolves over time. At date 1, the squatter receives a perfectly informative signal of the state. In other words, he will

\footnotetext{
${ }^{12}$ The local squatter may not need to employ a trademark agent or lawyer.
} 
know whether the state is good or bad with probability one. This assumption captures, in an extreme but nonetheless clear way, the simple idea that the squatter has more knowledge than the brand owner about the local conditions of the market. In Appendix A.1 we relax this assumption by considering a less extreme form of informational advantage. Lastly, at date 2, the brand owner also learns the true state of the market.

\subsection{The Cancellation-Negotiation Phase}

This final stage of the game only takes place if the squatter manages to register the trademark. The brand owner must then decide among the following three alternatives 13

a. Do nothing;

b. Request a cancellation of the squatted trademark; or

$c$. Negotiate with the squatter to buy the squatted trademark.

By doing nothing, the brand owner gets a zero payoff. In other words, the brand owner will get no benefit if he does not use the brand to commercialize his product.

Requesting a cancellation is costly and risky. The brand owner cannot be sure of whether the squatted trademark will be cancelled or not. Besides he will have to cover procedural fees and his lawyer's honorarium. Let $k$ and $\tilde{h}$ be respectively the expected cost and the expected profit of requesting a cancellation. Clearly, as the squatted trademark will not be cancelled for sure, $\tilde{h} \leq h$. In summary, the expected payoff of the brand owner when requesting a cancellation is $\tilde{h}-k$.

The squatter's payoff when the brand owner chooses either to do nothing or to request cancellation of the trademark is zero. In other words, the squatter gets no rents from using the trademark himself. His benefits come exclusively from selling the squatted trademark to the brand owner.

Lastly consider the negotiation option. In this case, we assume that the payoff to the brand owner and squatter are determined by the solution of a generalized Nash bargaining game ${ }^{14}$ Consequently, the disagreement point $d \equiv\left(d_{1}, d_{2}\right)$ will be given by the payoff vector associated to either one of the previous alternatives that gives the maximum payoff to the brand owner.

\footnotetext{
${ }^{13}$ The brand owner might also infringe the squatted trademark. We implicitly assume that this option is less profitable than requesting a cancellation procedure. This assumption does not affect our main results and simplifies our calculations substantially.

${ }^{14}$ For an extensive discussion of Nash bargaining see, for instance, Muthoo (2002).
} 


\subsection{Equilibrium Without Squatting}

What is the optimal registration strategy of the brand owner when there is no squatting activity? This is a simple decision problem that we solve using backward induction.

Suppose that the brand owner has not registered the brand at date 0 . Since at date 2 he learns the state of the market for sure, it follows from Assumption (A1) that he will register the brand only if the state is good. So, the expected (discounted) value of registering the brand at date 2 , hereafter the value of waiting, is ${ }^{15}$

$$
w_{1}=\mu\left(h-c_{1}\right)
$$

On the other hand, the value of registering the brand at date 0 , hereafter the anticipatory value, is:

$$
v_{1}=\mu h-c_{1} .
$$

With the net value of waiting being:

$$
w_{1}-v_{1}=(1-\mu) c_{1}>0
$$

it follows that:

Proposition 1 (Optimal registration without squatting). The brand owner will wait up to date 2 to register the brand.

Thus, in the absence of squatting, brand owners register their brands at the last date of the application phase and, of course, only when the market thrives. The intuition is simple. Waiting allows the brand owner to tailor his registration decision to contingency, in particular to avoid registering the brand when the market is in the bad state. To reaffirm this intuition, observe that the net value of waiting is increasing in $c_{1}$ : the higher the cost, the larger the gains from avoiding registration when the state is bad.

\subsection{Equilibrium With Squatting}

We examine here the equilibria of our model when there is squatting activity, that is when $\xi>0$. By equilibrium, we mean subgame perfect Nash equilibrium. We begin, using backward induction, by establishing the best decision of the brand owner in the cancellation-negotiation phase.

\footnotetext{
${ }^{15}$ Agents do not discount the future.
} 


\subsubsection{The Cancellation-Negotiation Phase.}

Let us assume that the squatter has managed to register the trademark. There are then two cases to consider:

a. Cheap cancellation system: in this situation, requesting a cancellation is, for the brand owner, better than doing nothing; i.e., $\tilde{h}-k>0$.

$b$. Expensive cancellation system: in this situation, requesting a cancellation is, for the brand owner, worse than doing nothing; i.e., $\tilde{h}-k \leq 0$.

To simplify our discussion, we deal here only with the arithmetically simpler case of negotiations under an expensive cancellation system. We look at the cheap cancellation system in Appendix A.2

Under an expensive cancellation system, if negotiations end up in disagreement the brand owner will do nothing. Hence, the reservation or disagreement payoffs for the negotiations are given by $d=(0,0)$. It results then that the price $p$ at which the trademark will be sold to the brand onwer solves:

$$
\max _{p \geq 0}(h-p)^{1-\tau}(p)^{\tau}
$$

where we interpret $\tau \in(0,1)$ as the relative bargaining power of the squatter. When $\tau \approx 0$ all the bargaining power lies in the hands of the brand owner. The unique price that solves the above problem is:

$$
p^{*}=\tau h,
$$

and hence payoffs for the brand owner and the squatter respectively are:

$$
\begin{aligned}
& n_{1}=h-p^{*}=(1-\tau) h, \\
& n_{2}=p^{*}=\tau h .
\end{aligned}
$$

Clearly, as payoffs are positive, the agents will get an agreement to exchange the squatted trademark at the equilibrium price $p^{*}$. Note, for instance, that when the squatter has almost all the bargaining power, the payoff to the brand owner is approximately equal to his disagreement or reservation payoff; i.e., zero. Similarly, when the brand owner has almost all the bargaining power, the price is close to zero and the squatter gets nothing for his squatted trademark. 


\subsubsection{The Application Phase}

Let us now take the perspective of the squatter at date 1 when the state is good. The payoff that he obtains by filing a trademark application is:

$$
\pi_{2}=\lambda n_{2}-c_{2}=\lambda \tau h-c_{2}
$$

Note that this payoff depends positively on the brand owner's profits. The higher these profits - or the more valuable the brand - the stronger the incentive to squat. In addition, with a sufficiently high $h$, squatting will be profitable even if the the chances of success $\lambda$ are relatively low. We will use these insights when developing our squatter identification methdology in Section 5 .

Going backwards, we can derive the value of waiting and the anticipatory value for the brand owner. Let us begin with the latter. Observe that the anticipatory value is independent of the existence of squatting since by registering the brand at date 0 , the brand owner ends the game. Thus, the anticipatory value is still given by equation (2).

How does the presence of squatting activity affect the value of waiting? To answer this question, assume that squatting is profitable since otherwise nothing changes. Also let the state of the market be good. On the one hand, the brand owner will obtain a payoff equal to $h-c_{1}$ if he manages to register the brand at date 2. This event occurs when either: (i) There is a squatter but his application is rejected by the trademark office; or: (ii) There is no squatter. Therefore, the total probability of this event is:

$$
\mu \xi(1-\lambda)+\mu(1-\xi)
$$

On the other hand, the brand owner will get a payoff equal to $n_{1}$ when the squatter is available and his trademark application is accepted by the trademark office. The probability of this event is:

$$
\mu \xi \lambda \text {. }
$$

Hence the vaule of waiting under squatting activity is:

$$
w_{1}^{*}=[\mu \xi(1-\lambda)+\mu(1-\xi)]\left(h-c_{1}\right)+\mu \xi \lambda n_{1} .
$$

After some simple mathematical manipulations and recalling that $w_{1}$ is the value of waiting without squatting activity, we arrive at:

$$
w_{1}^{*}=w_{1}-\mu \lambda \xi\left(\tau h-c_{1}\right) .
$$

Since it costs $c_{1}$ to the brand owner to register the brand but he has to pay $\tau h$ to the 
squatter, one can view $\mu \lambda \xi\left(\tau h-c_{1}\right)$ as the (expected) tax due to squatting activity ${ }_{16}^{16}$ In short, the value of waiting in the presence of squatting is equal to the value of waiting without squatting minus the tax imposed by the squatter.

We define a squatting active equilibrium to be a subgame perfect Nash equilibrium in which the following two conditions hold:

$a$. The brand owner waits up to date 2 to register his brand; and:

$b$. The squatter, after observing the good state, files a trademark application.

In this type of equilibrium squatting takes place with probability $\mu \lambda \xi$. The second condition is met if, and only if:

$$
\pi_{2}=\lambda \tau h-c_{2} \geq 0,
$$

or more briefly if, and only if, the squatter's cost is (weakly) smaller than $c_{2}^{*}$, the largest possible cost that makes squatting profitable:

$$
c_{2} \leq c_{2}^{*} \equiv \lambda \tau h .
$$

The first condition is satisfied if, and only if:

$$
w_{1}^{*}-v_{1}=(1-\mu) c_{1}-\mu \lambda \xi\left(\tau h-c_{1}\right) \geq 0,
$$

or, if and only if the brand owner's cost is (weakly) higher than $c_{1}^{*}$, the smallest possible cost that makes the net value of waiting positive:

$$
c_{1} \geq c_{1}^{*} \equiv \frac{\mu \lambda \xi}{\mu \lambda \xi+(1-\mu)} \tau h .
$$

As $c_{1} \geq c_{2}$ we have that:

Proposition 2 (Existence). A squatting active equilibrium exists if, and only if:

a. $c_{2} \leq c_{2}^{*} \leq c_{1}^{*} \leq c_{1} ;$ or:

b. $c_{1}^{*} \leq c_{2} \leq c_{1} \leq c_{2}^{*}$,

holds.

We interpret item $(a)$ as saying that a positive cost difference $c_{1}-c_{2}$ between the brand owner and the squatter enables squatting behavior. In other words, if the smallest pos-

\footnotetext{
${ }^{16}$ Of course $\tau h<c_{1}$ is possible, but we focus on the interesting case in which the tax is weakly positive.
} 
sible cost for the brand owner $c_{1}^{*}$ is higher than the smallest possible cost for the squatter $c_{2}^{*}$, squatting takes place only when the cost difference $c_{1}-c_{2}$ becomes sufficiently large.

Item $(b)$, however, emphasizes that squatting may even take place in the absence of any cost difference between the squatter and the brand owner. To further examine this case, let us set $c_{1}=c_{2}=c$. In addition, we define a pre-emptive equilibrium to be a subgame perfect Nash equilibrium in which the following two conditions hold:

$a$. The brand owner registers his brand at date 0 ; and:

$b$. The squatter, after observing the good state, files a trademark application.

Note that in this type of equilibrum squatting takes place with zero probability since the brand owner ends the game at date 0. More informally, in a pre-emptive equilibrium, the brand owner, anticipating the filing of a trademark application by the squatter, advances his registration decision to date 0 .

Similarly, we define a squatting free equilibrium to be a subgame perfect Nash equilibrium in which the following two conditions hold:

a. The brand owner waits up to date 2 to register his brand; and:

$b$. The squatter does not file a trademark application.

In this kind of equilibrium, squatting also takes place with zero probability. In other words, in a squatting free equilibrium the brand owner, anticipating that the squatter will not file a trademark application, waits to register his brand.

Finally, we make the following assumption:

$$
1<\lambda+\xi^{-1}\left(\mu^{-1}-1\right),
$$

which ensures that $c_{1}^{*}<c_{2}^{*}$; a necessary condition for the existence of a squatting active equilibrium. When Assumption (A2) holds we have:

Proposition 3 (Strategic squatting). If:

a. $0<c<c_{1}^{*}$, there is a unique pre-emptive equilibrium;

b. $c_{1}^{*} \leq c \leq c_{2}^{*}$, there is a unique squatting active equilibrium; and:

c. $c_{2}^{*}<c$, there is a unique squatting free equilibrium.

Proof. See Appendix A.4 
Proposition 3 states that three types of equilibria may exist. In the pre-emptive equilibrium, the brand owner anticipates that negotiations with the squatter will be too costly for him to wait. Hence, he registers the brand at date 0 under the shadow of uncertainty with respect to the future state of the market. Since with positive probability the state will be bad, many registered trademarks will never be used in the market.

In the squatting free equilibrium, the squatter anticipates that the (expected) selling price will be too low to cover his cost. As a result, the brand owner waits to register his brand at date 2 . This equilibrium is outcome equivalent to the optimal registration strategy in the absence of squatting activity, i.e., Proposition 1.

In the squatter active equilibrium the selling price and the squatter's costs are such that the squatter finds it profitable to squat a trademark application and the brand owner anticipates profits that lead him to wait and negotiate with the squatter for the squatted trademark.

We close this section by noticing that squatting activity may create distortions in the timing of the registration decisions. More precisely, in the pre-emptive equilibrium there is an inefficiently early registration by the brand owner. As a result, with positive probability, real resources are wasted since the registered trademark will not be used when the state is bad 17

\subsection{Comparative Statics}

In this section we continue assuming that $c_{1}=c_{2}=c$ and examine how the nature of the equilibrium depends on the parameters of the model. Let us denote with $\beta$ a generic parameter of our model. Recall that, from item (b) of Proposition 3, a squatting active equilibrium exists if, and only if, $c \in \mathrm{C} \equiv\left[c_{1}^{*}, c_{2}^{*}\right]$. We say then that $\mathrm{C}$ is the set of cost values that supports the squatting active equilibrium.

Definition 1 (Increasing-decreasing set). The set $\mathrm{C}$ is increasing in $\beta$ if either $c_{2}^{*}$ is weakly increasing in $\beta$ or $c_{1}^{*}$ is weakly decreasing in $\beta$. The set $\mathrm{C}$ is decreasing in $\beta$ if either $c_{2}^{*}$ is weakly decreasing in $\beta$ or $c_{1}^{*}$ is weakly increasing in $\beta{ }^{18}$

Note that the size of $\mathrm{C}$, measured by its length $c_{2}^{*}-c_{1}^{*}$, unambiguously increases as $\beta$ becomes larger. Our interpretation is that the higher $\beta$, the more likely the squatting active equilibrium is. Thus we say that the squatting active equilibrium is increasing

\footnotetext{
${ }^{17}$ In the squatting active equilibrium, the timing is 'optimal', although a redistribution of resources from brand owners to squatters takes place. Certainly, this does not cause any inefficiency in our simple model but it might in a more complex set-up since it increases the entry cost of brand owners.

${ }^{18}$ The word or is used in the nonexclusive sense, so that if both $c_{2}^{*}$ is weakly increasing (decreasing) in $\beta$ and $c_{1}^{*}$ is weakly decreasing (increasing) in $\beta$, set $\mathrm{C}$ is increasing (decreasing) in $\beta$.
} 
(decreasing) in $\beta$ if $\mathrm{C}$ is increasing (decreasing) in $\beta$. Note that if this equilibrium is increasing (decreasing) in $\beta$, then either the pre-emptive equilibrium or the squatting free equilibrium must be decreasing (increasing) in $\beta{ }^{19}$ Of course, it might well be that the squatting active equilibrium is neither increasing nor decreasing in $\beta$ according to our definition. For instance, it might be that both $c_{1}^{*}$ and $c_{2}^{*}$ increase with $\beta$. In that case, we say that the squatting active equilibrium is non-monotonic in $\beta$.

With this definition in hand, we can state the following:

Proposition 4 (Change in $\xi$ ). The squatting active equilibrium is decreasing in $\xi$. The preemptive equilibrium is increasing in $\xi$.

Proof. See Appendix A.5

The intuition is simple: as $\xi$ increases, squatting becomes more likely and thus the (expected) tax $\mu \lambda \xi\left(\tau h-c_{1}\right)$ imposed on the brand owner increases. As a result, the brand owner finds it more attractive to anticipate the registration of his brand to date 0 . In other words, if brand owners believe that squatting becomes more likely, their best response - to avoid the threat of being held-up - is to register their brands preemptively at the beginning of the game.

What type of brands are more likely to be targeted by squatters? Are famous brands less or more likely to be squatted? We have already seen above that the squatter's payoff is increasing in $h$, the value of the brand in the good state of the market. Here we look at other aspects involved in this question. First, we allow the probability of having success in the market place $\mu$ to be higher for well-known brands. In this case, the answer is given by:

Proposition 5 (Change in $\mu$ ). The squatting active equilibrium is decreasing in $\mu$. The preemptive equilibrium is increasing in $\mu$.

Proof. See Appendix A.6.

It should be intuitively clear that the net value of waiting decreases and that preemptive registration becomes more attractive as $\mu$ increases. Two reinforcing effects contribute to this result. On the one hand, the gains from delaying registration fall. On the other, the (expected) squatting tax, i.e., $\mu \lambda \xi\left(\tau h-c_{1}\right)$, increases as it becomes more likely that the brand be squatted at date 1. In short, counterintuitively Proposition 5 suggests that famous brands are less likely to be squatted.

Alternatively, we might think that squatting a well-known brand should be more difficult. The idea is simple: the trademark office should easily recognize the brand and

\footnotetext{
${ }^{19}$ Again the word or is used in the nonexclusive sense.
} 
reject the squatter's application. In our model this effect is captured by a decrease in $\lambda$, that is a decrease in the probability that the squatter gets his application granted. Proposition 6 confirms this intuition and it also sheds further light on the forces leading to this result.

Proposition 6 (Change in $\lambda$ ). The squatting active equilibrium and the pre-emptive equilibrium are increasing in $\lambda$.

Proof. See Appendix A.7.

To see what is behind this result, let us assume that $\lambda$ decreases. Then, on the one hand, the net value of waiting increases since it is less likely that the trademark office registers the squatter's application 20 But precisely because the trademark application by a squatter is less likely to get registered, the profitability of squatting also falls. The proposition shows that this second effect dominates the first one making the squatting active equilibrium less likely.

Next we ask whether squatting is more likely to take place for risky brands where risky means high payoff with low probability (i.e. a mean-preserving spread in market payoffs). Formally, we are interested in understanding the following experiment: increase $h$, the payoff in the good state, and decrease $\mu$ such that the expected market value of the brand remains constant:

$$
\mu h \equiv \text { Constant }
$$

Proposition 7 (Change in risk). The squatting active equilibrium is increasing in risk. Both the pre-emptive and the squatting free equilibrium are decreasing in risk.

Proof. See Appendix A.8

We interpret this result as saying that risky brands with a high market potential are more likely to be squatted. Intuitively, the net value of waiting increases since the arrival of bad news, i.e., the state being bad, becomes much more likely. On the other hand, as $h$ increases, the profitability of squatting also increases. These two effects reinforce each other leading to the result that risky brands should be squatted more frequently.

Finally, we look at the question whether more profitable brands are more likely to be targeted by squatters. We assume that, for highly profitable and well-known brands, market profits $h$ and the success probability $\mu$ are positively correlated. We capture this idea by using the simplest possible model of association between them ${ }^{21}$ We

\footnotetext{
${ }^{20}$ It is this effect that makes the pre-emptive equilibrium less likely.

${ }^{21}$ For a classic introduction to dependence concepts, see Lehmann (1966).
} 
assume that $\mu$ is positively regression dependent on $h: \mu \equiv \alpha+\gamma h$ for $\alpha>0$ and $\gamma \geq 0$ such that $\mu \in(0,1)$. Observe then that when $\gamma=0$ we are back in our original model with $\mu=\alpha$. It is thus not difficult to show that our previous qualitative results still hold in this slightly more general framework. This allows us to state:

Proposition 8 (Change in profitability). There exists $a \gamma^{*}$ such that:

a. If $\gamma<\gamma^{*}$, the squatting active equilibrium is increasing in $h$.

b. If $\gamma \geq \gamma^{*}$, the squatting active equilibrium is decreasing in $h$.

Proof. See Appendix A.9

The intuition behind Proposition 8 is simple. Suppose that $h$ goes up. This, on the one hand, makes squatting more profitable. However, on the other hand, the brand owner has also higher incentives to pre-emptively register his brand. This follows because, as $\mu$ and $h$ increase, the net value of waiting decreases. When $\gamma$ is sufficiently high, the second effect dominates the first one and more profitable brands are less likely to be squatted. However as the correlation between $h$ and $\mu$ falls, chances of observing the squatting active equilibrium also improve.

\section{Trademark System in Chile}

This section describes the legal framework of the Chilean trademark system with a view to explaining how trademark squatting is viable from a legal point of view and what mechanisms the Chilean system offers to counter squatting behavior.

\subsection{Application Procedure}

The procedure for registering a trademark in Chile has three stages ${ }^{22}$ (i) the filing of an application and its formal examination, (ii) its publication in the gazette and (iii) a substantive examination. The total processing time of an application until its registration takes a minimum of approximately six month, though it can take longer - especially if it is subject to opposition procedures. The application fee is around US\$ 85 per class ${ }^{23}$ The formal examination only ensures that an application meets the formal requirements but does not provide any assessment with regard to the merits of the application. If an application meets the formal requirements, it is published in

\footnotetext{
${ }^{22}$ The application and registration of trademarks in Chile is governed by Law 19.039 enacted in January 1991. The Law was amended in 2005 and 2007 by Laws 19.996 and 20.160.

${ }^{23}$ Note that before 2012, applicants could only apply for product or service classes, but not a combination of both. Still, applicants could apply for several classes but only within the product or service categories.
} 
the gazette and a publication fee is payable. Once published, the application can be opposed. If a trademark is not opposed, it proceeds to the substantive examination which assesses the application on absolute and relative grounds. If an application successfully passes the substantive examination, the trademark is registered. At this point, another fee of around US\$ 170 per class is payable.

Note that because Chile is not a member of the Madrid System for the International Registration of Marks, non-resident applicants have to file directly with INAPI to obtain a trademark in Chile.

\subsubsection{Well-known brands}

One of the most relevant legal barriers to squatting is the protection of well-known trademarks established by Article 6bis of the Paris Convention and Article 16.2 of TRIPS. INAPI has implemented this obligation in its Intellectual Property Law 19.039 of 1991.

If a third party wants to oppose or have a trademark canceled based on grounds of a well-known brand, the burden of proof relies on the complainant. In its assessment, INAPI considers registrations of the trademark abroad and the Nice classes that the related products and/or services cover. A foreign trademark registration protecting the trademark in question must be in force at least on the date of filing of the opposition. The number of registrations in different foreign countries is also taken into account in the assessment of whether a trademark is well-known. However, it may be still possible to establish that a brand is well-known if no previous registrations exist in the same Nice class but only in a related Nice class ${ }^{24}$

\subsubsection{Opposition}

Once the application is published in the gazette, there is a 30 day period in which third parties can file an opposition. In principle, anyone can file an opposition (Art. 5) and the filing of an opposition is not subject to any fee payment. However, the opposing party has to be represented by an attorney, which imposes costs on the opposing party.

\subsubsection{Substantive examination}

INAPI substantially examines trademark applications and where an application was opposed considers the information generated by the opposition proceedings.

\footnotetext{
${ }^{24}$ In fact, there is even the possibility to establish that a brand is well-known when the trademark was registered abroad only after the application is challenged in Chile. In these cases, the brand owner has to establish that the brand had been used extensively in the past and that the registration of the trademark would be misleading or lead to consumer confusion.
} 
Importantly, there is no legal requirement in Chile for demonstrating any use or intent to use - of a trademark; this differs from several other jurisdictions, like the U.S., which require proof of (intent to) use for a trademark to be registered.

There are absolute and relative grounds for rejection of a trademark application. Absolute grounds relate to the question whether the trademark constitutes trademarkable subject matter. Relative grounds, in turn, refer to the existence of other rights that could give rise to confusion. Examiners at INAPI commonly search INAPI's trademark register for registered or pending trademarks that are similar to the applied trademark. Searches focus on the Nice class(es) in which the applicant requested protection as well as related classes in which there may be concerns about consumer confusion 25

\subsection{Post-registration cancellation of trademarks}

Any person can request cancellation of a registered trademark (Art. 18bis g). The request has to be filed with INAPI within five years after the trademark was registered. This restriction does not apply to trademarks that were obtained in bad faith (which can include squatting), but the burden of proof of bad faith is on the party requesting the cancellation of a registered trademark.

\section{Data}

We have data on the complete Chilean trademark register for all trademark filings with INAPI between 1991 and 2010. The register contains around 575,000 trademark filings by residents and non-residents between 1991 and 2010. We harmonized applicant names, which means, we are able to uniquely identify applicants. ${ }^{26}$

Our database contains detailed information on trademarks, including application, publication, and registration dates, Nice classes, priority information, information on trademark types, detailed information on the legal status of a trademark including information on oppositions and cancellations. While basic information on oppositions and post-registration cancellations was available in digitized format, the identity of the opposing party and that requesting cancellation of a registered trademark had to be obtained directly from the case files which had to be digitized for the purposes of our study. Our ability to uniquely identify applicants also allowed us to classify applicants into different categories: companies, individuals, universities and research

\footnotetext{
${ }^{25}$ INAPI maintains guidelines which provide information on how different product and service classes relate to one another.

${ }^{26}$ For detailed discussion of the data construction as well as descriptive evidence see see Abud et al. (2013).
} 
institutions, as well as government entities. We also use a mapping of Nice classes into sectors corresponding to economic activities by Edital ${ }^{27}$

\section{Identifying squatters in the trademark register}

\section{1 'Squatter algorithm'}

As discussed in Section 2, the business model of squatters rests on the ability to register a trademark on a product or trading name that either already is successful in the market place but has not been registered yet in a given jurisdiction or that may be successful in the (near) future. Often a combination of both factors is at play, that is, a trademark that has been successful in one jurisdiction and the squatter attempts to register it in another jurisdiction expecting market entry to occur eventually. Alternatively, a squatter may attempt to register a trademark in a class other than the ones in which the brand owner has registered the trademark.

Motivated by the framework developed in Section 2, we define ten criteria to identify squatters in the trademark register. These criteria cover characteristics of the trademark, its owner, as well as legal events such as pre-grant oppositions or post-grant cancelations. Appendix B discusses these criteria in detail. We use the combination of these criteria to compute an overall 'squatter score,' which is the simple average of the different criteria whose individual scores we standardized. We limit the final set of applicants to those with at least two trademark filings. In addition, we manually check all of the potential squatters picked up by at least one of the criteria for false positives 28

It is important to stress that our approach is conservative in the sense that it is most likely to pick up 'professional' squatters. Companies that overwhelmingly use the trademark system to protect their own brands but have a few squatted trademarks in their portfolio are not picked up by our algorithm. Instead we focus on companies and individuals whose main business model is squatting. Also, there may well be a considerable number of squatters with less than two trademark filings, which we do

\footnotetext{
${ }^{27}$ Edital groups Nice classes into the following economic activities: Agricultural products and services: 29, 30, 31, 32, 33 , 43; Chemicals: 1, 2, 4; Construction, Infrastructure: 6, 17, 19, 37, 40; Household equipment: 8, 11, 20, 21; Leisure, Education, Training: 13, 15, 16, 28, 41; Management, Communications, Real estate and Financial services: 35, 36; Pharmaceuticals, Health, Cosmetics: 3, 5, 10, 44; Scientific research, Information and Communication technology: 9, 38, 42, 45; Textiles - Clothing and Accessories: 14, 18, 22, 23, 24, 25, 26, 27, 34; Transportation and Logistics: 7, 12, 39.

${ }^{28}$ In selected cases, it was ambiguous whether the applicant could be a foreign trademark holder's official agent or otherwise applied for the trademark with the holder's consent. Most of those cases could be resolved through web searches or opposition information. In a few cases, no such additional information was available and we retained the applicant as a squatter interpreting the absence of any information as a sign indicative of squatting.
} 
not pick up. At the same time, they are less likely to have a systematic impact on brand owners and hence are less relevant for our analysis.

\subsection{Results}

Table 1 shows how the squatters identified by our algorithm compare to all remaining applicants according to the nine characteristics described above. Note that since we used precisely those characteristics to identify squatters, the resulting differences between the two groups of applicants could be upward biased. That said, there may well be squatters not picked up by our characteristics - especially applicants that for the most part use the system 'legitimately' and squat only occasionally ${ }^{29}$ At the same time, significant differences across all nine characteristics are not mechanistic, as the selection of squatters ultimately relied on the combination of all criteria and additional manual cleaning.

Notwithstanding these caveats, the table reveals interesting patterns. To begin with, squatter scores are significantly higher than other applicants' scores for nearly all characteristics, regardless of whether we look at companies or individuals. Opposition, invalidation, and rejection rates appear to be particularly informative in identifying squatters. Squatters' rejection rates of $65 \%$ for companies and $68 \%$ for individuals are large - it means that almost seven out of ten applications are rejected. This suggests that the existing institutional mechanisms go a long way in preventing squatting behavior, even if they cannot entirely prevent it. The opposition rates of $32 \%$ for companies and $38 \%$ for individuals are also very high - the opposition rate for all other applications is only half as large. Post-grant cancellations are rare - they occur only in less than $0.4 \%$ of all filings. However, they are lot more frequent among squatted trademarks: $6 \%$ for companies and $10 \%$ for individuals. In contrast, the diversity of Nice classes across applications is surprisingly uninformative for the identification of squatters. The statistics suggest that squatters, on average, do not file across a broader range of Nice classes than all other individual or corporate applicants; in fact, all other corporate applicants file trademark applications across a broader range than corporate squatters. As explained further below, this is largely due to a focus of squatters on brands related to clothes and accessories.

The lower score for the priority indicator means that there are relatively fewer trademarks among the applications by squatters that claim priority based on a prior foreign filing ${ }^{30}$ The other binary characteristics, type of use (product/service or com-

\footnotetext{
${ }^{29}$ This implies that there may be a downward bias in the differences between squatters and all other applications.

${ }^{30}$ For this criterion, the 'squatter algorithm' only selects applicants that do not claim priority at all. The fact that there are a few applicants that claim priority in the set of squatters identified by the algorithm
} 
mercial/industrial establishment), whether the trademark protects a product (as opposed to a service), and whether the applicant's trademark portfolio includes a famous brand, show that squatters have a lot more trademarks in their portfolios that match these characteristics. Especially the 'famous brand' identifier predicts squatters well.

This is also confirmed by estimates obtained from a simple regression where we regress a dummy variable which indicates whether a company is a squatter on the various criteria as well as a dummy variable that is equal to one if the applicant is a company. The results are shown in Table 2. Looking at the estimates of the linear probability model, the results show that individuals are more likely to squat. Also all criteria are positively associated with squatting, except for the priority and type of use criteria; as discussed above, the negative sign on the priority variable has to be be interpreted as suggesting that the larger the share of trademarks that claim priority, the less likely an applicant is a squatter. The 'top brand' variable is a binary variable, which means we can interpret its coefficient to say that applicants that have any trademarks in their portfolio that are also in the portfolio of applicants that have at least one trademark application on a famous brand (without being the brand owner), are almost $10 \%$ more likely to be squatters. The results for the logit model are qualitatively largely the same except for the priority dummy losing its significance and the type of use variable becoming marginally significant.

Based on the various characteristics, we identify a total of 432 squatters, 88 companies and 344 individuals. The fact that the great majority of squatters are individuals is consistent with Proposition 2 in Section 2, which showed how cost differences give rise to squatting opportunities. Individuals are less likely to employ third party agents when filing trademark applications, thus facing substantially lower costs than larger and especially foreign companies.

These squatters filed together almost 5,800 trademark applications between 1991 and 2010 (nearly 1,530 applications by companies and 4,270 applications by individuals). Figure 3 plots total filings by squatters over time and shows the filings as a percentage of total filings. The figures suggest that the squatting activity peaked in 1996 and 1997 with 461 and 553 filings, respectively. Filings dropped in 1998 and remained at an average of around 230 filings annually during the subsequent period. The figure also shows that the number of filings as a percentage of total filings tracks the absolute number of filings very closely throughout the 20 -year period. The share fluctuates between $.5 \%$ in 2008 and $1.8 \%$ in 1997 with an average of $1 \%$ for the entire 1991-2010 period. Figure 4 provides information on the type of trademarks that have been squatted. For Figure 4 , we map the 45 Nice classes into broad economic is due to the fact that we use the combination of all criteria. 
activities (see Section 4). The figure compares the distribution of trademark filings across economic activities for squatted and all other trademark filings. The distribution shows that squatters concentrate disproportionately on clothing and accessories related trademarks. Famous brands concerned cover a wide range including Abercrombie \& Fitch, Adidas, Barbour, Billabong, Chanel, Facebook, Google, Metallica, various sports teams, etc. Although not shown in Figure 4, when we break down squatter filings across the 45 Nice classes, the concentration on clothing is confirmed as most filings are concentrated in Class 25 (clothing, footwear, headgear) whereas we also note a complete absence of filings in Class 45 (legal services) which lends further credibility to our 'squatter algorithm.'

\section{The effect of squatters on brand owners - empirical approach}

We assess the effect of squatting on brand owners from two angles. The first concerns the potential preemptive filing of trademarks by brand owners in reaction to squatting. We assess this by looking at changes in filing behavior after brand owners oppose a squatted trademark. The second concerns how brand owners react to the need of having to remove a squatted trademark from the register post-registration.

\subsection{Preemptive filings}

Our model in Section A.3 suggests that brand owners are more likely to preemptively file for trademarks the larger $\xi$ - the likelihood of encountering a squatter (Proposition 4). Moreover, an increase in the likelihood $\lambda$ that a squatter successfully passes the substantive examination stage also increases the incentives for brand owners to file preemptively (Proposition 6). Although the model does not directly translate to a dynamic setting where brand owners change their filing behavior over time, the model still suggests that we should see an increase in trademark filings as brand owners learn first hand about the existence of squatters and that the squatters successfully register squatted trademarks with the trademark office.

There are several possible mechanisms that can lead to such an increase in trademark filings by brand owners as a response to squatting. One such mechanism is an increase in the general perception of the importance of protecting one's brands by trademarks. This would imply a positive correlation between trademark filings and squatting activity. However, squatting can also lead to a change in trademarking strategies by brand owners. Even if a brand owner has already been protecting its core brand(s) by trademarks, having been exposed to squatting could lead to more trademarks filings if brand owners start 'fencing' their core brands through a multitude of 
related trademarks. This strategy could also involve covering more Nice classes than strictly needed given the nature of the product or service marketed. Since during our study period, the Chilean trademark system is characterized by the absence of a use requirement, brand owners were free to choose as many classes as they liked without having to prove use.

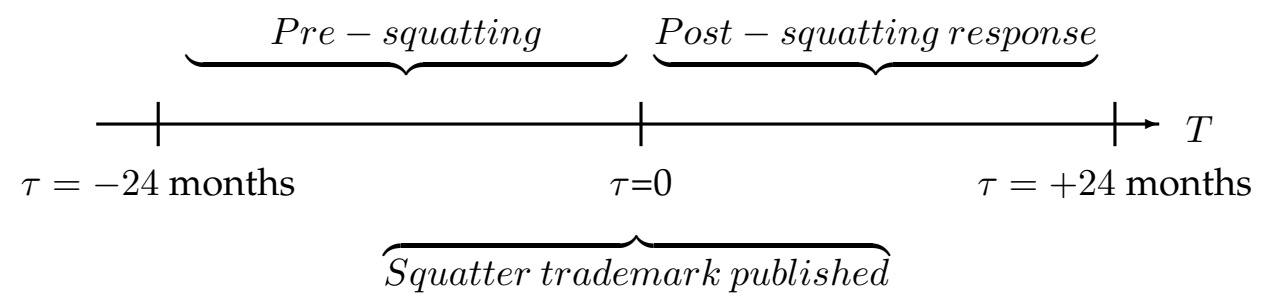

Figure 1: Event study timeline

To study the effect of squatting on preemptive filings we need to identify companies affected by squatters. Since transactions between brand owners and squatters are largely unobservable to us, we resort to opposition data ${ }^{31}$ In oppositions to the registration of trademarks owned by squatters, a brand owner reveals not only his identity, but he also signals that blocking the registration of the trademark is valuable to him since - as explained above - opposition proceedings involve direct and indirect costs. To study the reaction by brand owners, we adopt an event study approach. As shown in Figure 1, we analyze whether the publication of a squatter's trademark application that triggered an opposition procedure is followed by a change in trademark filing behavior of the affected brand owner (note that Section A.3 in the appendix shows that the results of our model in Section 2 are robust to incorporating an opposition stage). To capture the timing of events more closely, we switch from annual to quarterly trademark counts and define the estimation window to be 24 months before and after publication of a squatter trademark ${ }^{32}$

We define an index $\tau$ that ranges from 24 months before the opposition of a trademark to 24 months after the opposition. $\tau$ therefore ranges from -24 to +24 where $\tau=0$ denotes the month in which a squatter trademark was published (opposition occurs within 30 days counting from publication) ${ }^{33}$

To illustrate our approach, Figure 2 shows the example that involves the U.S. Na-

\footnotetext{
${ }^{31}$ We have some, albeit very limited, data on trademark reassignments. But as discussed above, due to the absence of a legal requirement to register re-assignments or licensing contracts with INAPI, the data is selective and therefore unrepresentative.

${ }^{32}$ For robustness, we also obtain results for different definitions of the estimation window.

${ }^{33}$ Defining the event date as the date of publication instead of opposition avoids the potential problem of endogeneity of the precise filing date of an opposition and the occurrence of multiple opposition dates in case of several opposition filings on the same trademark.
} 
Figure 2: The NBA's response to squatting

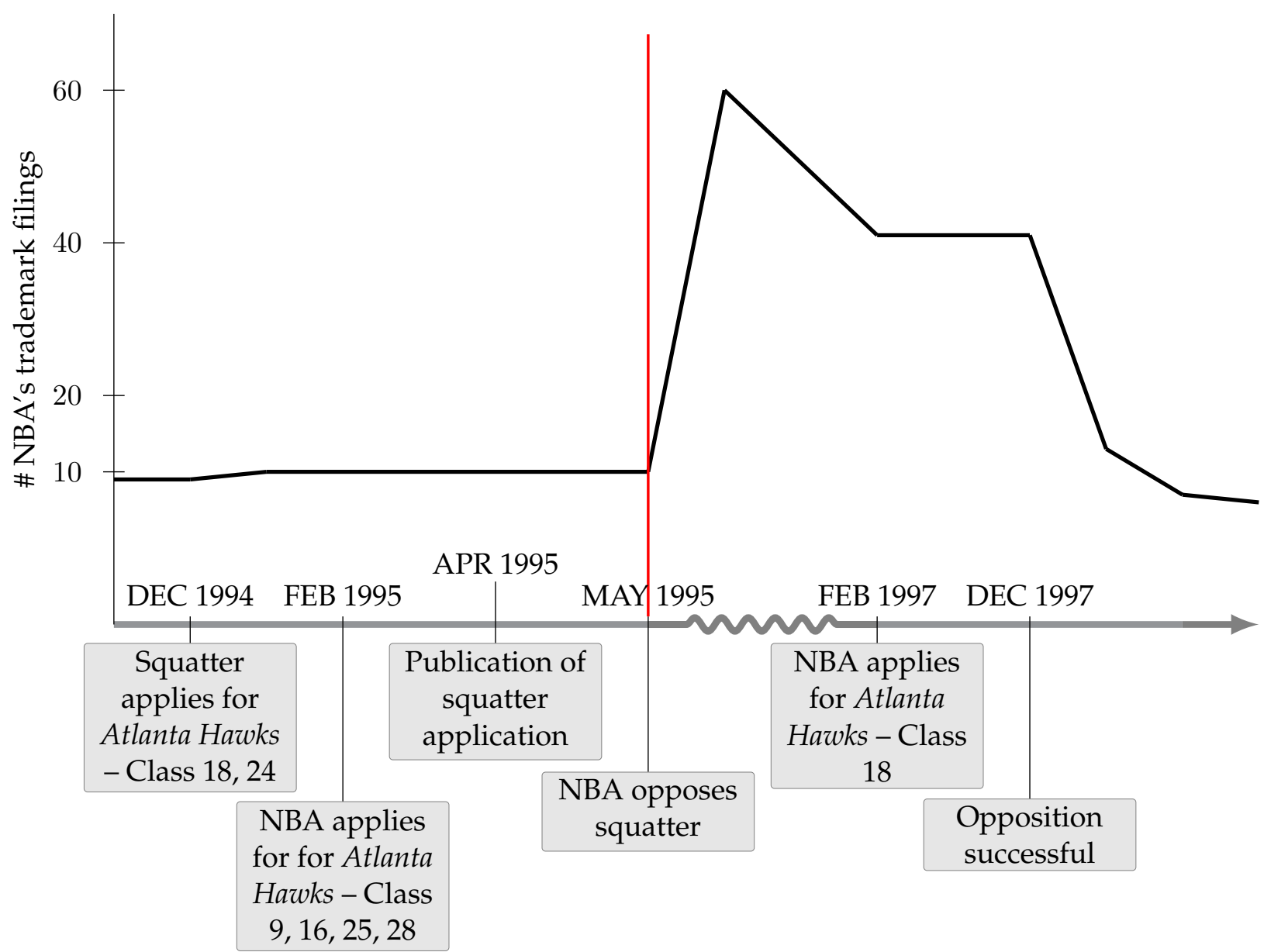

tional Basketball Association (NBA). Qian y Chien Ltda., a company that has (un)successfully attempted to register trademarks on a range of well-known foreign brands, filed a number of trademark applications in December 1994 to protect 16 different NBA team names. For example, Qian y Chien Ltda. filed a trademark application to protect 'Atlanta Hawks' (the Atlanta NBA team) on December 26, 1994. The trademark application was published on April 26, 1995. Interestingly, the NBA filed its own trademark on 'Atlanta Hawks' in February 1995, even before Qian y Chien's application was published - but in different classes than Qian y Chien ${ }^{34}$ Following the publication of Qian y Chien's trademarks on the various NBA team names in April 1995, the NBA opposes their registration in May 1995. For the Atlanta Hawks trademark opposition, the decision on the opposition was handed down one and a half years later on Decem-

\footnotetext{
${ }^{34}$ Qian y Chien requested classes 18 and 24 (leather goods, textiles) whereas the NBA requested classes $9,16,25$, and 28 (recording media, paper \& cardboard, clothing, and games).
} 
ber 1, 1997. The NBA prevailed and Qian y Chien's application was rejected ${ }^{35}$ This illustrates the substantial time lag required by opposition procedures in 'clearing the way' even when brand owners are able to invoke the 'famous and renowned' brand argument. Next, the NBA registers 'Atlanta Hawks' itself in class 18 - the trademark is registered in March 1999. In fact, the NBA had already filed the trademark application for 'Atlanta Hawks' in class 18 in February 1997 - in anticipation of the decision by INAPI on its opposition. This early application is in fact part of a drastic increase in trademark filings by the NBA beginning in 1996 following the initiation of opposition procedures against Qian y Chien. Figure 2 shows that large and sudden spike in trademark filings by the NBA in 1996 and 1997. On the one hand, this increase was due to the filing of trademarks on the team names squatted by Qian y Chien. On the other, the increase was due to the filing of a large number of trademarks on NBA brands so far not protected by trademarks in Chile as well as the filing of applications on brands already protected in Chile but in additional classes. The number of trademark filings by the NBA drops again in 2008 to reach levels prior to the Qian y Chien opposition. In summary, the NBA example shows how squatters may attempt to squat a well-known foreign brand, which may trigger an opposition by the brand owner. This experience, in turn, leads the brand owner to substantially change its filing behavior.

One could argue that brand owners generally display a pattern of increased filings post-opposition (although there is no evidence for that in our data - in fact, as shown below, the opposite is the case). To isolate the effect of squatters from confounding effects, we use a differences-in-differences approach where we match a control group of applicants to the set of applicants affected by squatters. We obtain the control group by matching on the opposed squatted trademarks based on the following trademark characteristics: filing year, trademark type, trademark use, existence of priority filing, and Nice classes. With the control sample at hand, we then estimate the following differences-in-differences specification:

$$
t m_{i \tau}=\alpha+\beta_{s} O_{i \tau=0} \times S Q_{i}+\beta_{o} O_{i \tau=0}+X_{i \tau}+\mu_{i}+\theta_{\tau}+\varepsilon_{i \tau}
$$

where $t m_{i \tau}$ denotes filings by brand owner $i$ in $\tau$ (including brand owners opposing a squatted trademark filing as well as 'control brand owners' opposing a filing by a 'legitimate' applicant), $\mu_{i}$ are applicant-level fixed effects, $\theta_{\tau}$ is a time trend, and $X_{i \tau}$ are applicant-level controls. $O_{i \tau=0}$ is a dummy variably which is equal to one once a brand owner opposed a trademark for the first time. We focus on a brand owner's first

\footnotetext{
${ }^{35}$ The NBA argued not only that its 'Atlanta Hawks' brand is well-known (Law 19.039 Article $20 \mathrm{~g}$ ), but also relied on an existing trademark in Chile that protected the word mark 'Atlanta' in the same class as Qian y Chien's application (Law 19.039 Article $20 \mathrm{~h}$ ) although this trademark was owned by a third party unrelated to the dispute.
} 
opposition as this is most likely the moment when a brand owner becomes aware of the threat posed by squatters (i.e. this is when brand owners adjust their $\xi$ and $\lambda$ upward). In addition, this approach helps addressing reverse causality concerns, that is, if brand owners indeed file trademarks preemptively in the presence of squatters, the need for oppositions should be reduced. $S Q_{i}$ identifies brand owners that opposed a squatted trademark. Since the sample contains applicants that were directly affected by squatters $\left(S Q_{i}=1\right)$ as well as unaffected applicants (the control sample $S Q_{i}=0$ ), $\beta_{s}$ is a differences-in-differences estimate of the squatter effect on the trademark filing behavior of brand owners targeted by squatters. We estimate Equation 11 using OLS, which makes the interpretation of interaction effects straightforward ${ }^{36}$

Next, to investigate the occurrence of trademark fencing as a response to squatting, we analyze potential changes in the coverage of trademarks across Nice classes. The idea is simple, if squatting leads to a disproportionate increase in trademark filings post-opposition, fencing is more likely to occur if brand owners extend their trademark protection even into areas not directly related to the product/service offered by the brand owner. Returning to the example of the NBA discussed above, after its first opposition to Qian y Chien's squatting attempts, the NBA filed trademarks in three classes that it had not previously considered (a $60 \%$ increase in the number of classes covered) ${ }^{37}$ even including a class entirely unrelated to the products commonly associated with the NBA 38

We do two things to investigate this for the entire sample. First we estimate a specification similar to (11) above with the difference being that the dependent variable nice $_{i \tau}$ is a binary indicator that is equal to one in $\tau$ if brand owner $i$ filed in a new Nice class - where new is defined as a class in which the brand owner had not yet obtained a trademark. All other variables are defined as in Equation (11).

$$
\text { nice }_{i \tau}=\alpha+\beta_{s} O_{i \tau=0} \times S Q_{i}+\beta_{o} O_{i \tau=0}+X_{i \tau}+\mu_{i}+\theta_{\tau}+\varepsilon_{i \tau}
$$

Second, we estimate an equation where the dependent variable, $a c t_{i \tau}$, is equal to one if the brand owner files in a Nice class that belongs to one of the broad economic sectors defined above that is unrelated to the brand owner's main business activity. The main business activity in turn is defined as the broad economic sector in which a brand owner had filed most trademarks before its first opposition.

\footnotetext{
${ }^{36}$ Interpreting interaction effects in non-linear models is not straightforward, see Ai and Norton (2003). Note that results are qualitatively the same using OLS with the log of trademark filings as the dependent variable or using a negative binomial model.

${ }^{37}$ Before the squatting attempt, the NBA had registered trademarks in five classes

${ }^{38}$ The unrelated class is 42 (scientific and technological services). The other classes are 24 (textiles and textile goods, not included in other classes; bed covers; table covers) and 18 (leather and imitations of leather) which is the class in which the squatter attempted to register the names of the NBA teams.
} 


$$
a c t_{i \tau}=\alpha+\beta_{s} O_{i \tau=0} \times S Q_{i}+\beta_{o} O_{i \tau=0}+X_{i \tau}+\mu_{i}+\theta_{\tau}+\varepsilon_{i \tau}
$$

Again, all other variables are as in Equation (11).

\subsection{Post-registration cancellations}

Oppositions have to occur within 30 days from the publication date of a trademark. Hence, brand owners interrupt a squatter's attempt to (mis)appropriate a brand early in the registration process - even before the substantive examination is carried out by the trademark office. Next, we ask what happens when brand owners learn or become concerned about a squatted trademark only after it was successfully registered with the trademark office. In such instances, brand owners can either enter an agreement with the squatter to re-assign or license the trademark, or they can attempt to get it cancelled from the register. The cancellation of a trademark, however, may be difficult because the party requesting cancellation has to prove that the trademark office did not take relevant information into consideration during the substantive examination stage - possibly because it was not available to the office - or the office made a mistake in its assessment.

We employ our data on trademark cancellations to conduct a parallel analysis to the one presented above on opposed trademarks. That is, we analyze whether trademark filings by brand owners change following the request for cancellation of a squatted registered trademark. As we did for oppositions, we construct a control sample of brand owners that attempt to cancel a registered trademark by other 'legitimate' brand owners and run the following differences-in-differences specification:

$$
t m_{i \tau}=\alpha+\beta_{s} C_{i \tau=0} \times S Q_{i}+\beta_{c} C_{i \tau=0}+X_{i \tau}+\mu_{i}+\theta_{\tau}+\varepsilon_{i \tau}
$$

where all variables are defined as in Equation (11) except for $C_{i \tau=0}$ which denotes a dummy variable equal to one once a brand owner filed a cancellation request for the first time ${ }^{39}$

If we find a positive effect on trademark filings by brand owners after having requested the cancellation of a squatted trademark, we might interpret this as evidence for some brand owners failing to monitor the Chilean trademark register (deliberately or not) and only taking action once the squatted trademark presents a real threat to the company's business. If we do not find any effect, the interpretation would be that, provided brand owners react to squatting, they do so at an earlier stage of the life of a squatted trademark - immediately after the publication of the squatted trademark.

\footnotetext{
${ }^{39}$ We use the date of the filing of the cancellation request as the event date.
} 


\section{The effect of squatters on brand owners - results}

\subsection{Preemptive filings - Oppositions}

There are a total of 1,635 trademark filings by squatters that were opposed by 1,146 distinct entities 40 Figure 5 plots the number of opposed trademarks as well as the number of distinct opposing parties over the sample period. There are on average around 100 opposed squatted trademarks per year over the sample period, although there is substantial variation. Overall, the number of entities filing the oppositions tracks the number of oppositions closely, which shows that parties file on average only slightly more than a single opposition in any given year ${ }^{41}$ Out of the 1,251 opposing parties, 1,009 filed at least one trademark application during the 1991-2010 period. In our analysis, we focus on these entities, although the regression sample is slightly further reduced due to the fact that we use \pm 24 and \pm 36 months time windows. This set of opposing parties consists of 827 companies (82\%), 173 individuals (17.1\%) and seven universities $(0.7 \%)$ and two (local) government entities $(0.2 \%)$.

The upper panel of Table 3 shows a comparison of average trademark filings preand post-opposition for brand owners that opposed a squatted trademark and those that opposed trademarks by other brand owners. The table shows that filings increase post-opposition only in the case of brand owners that opposed squatted trademarks (regardless of whether the time window analyzed is \pm 24 or \pm 36 months). On average, trademark filings by brand owners increase from around 1.2 filings for the 2-year period before a brand owner opposed a squatter application to nearly 1.6 filings over the 2-year period following the opposition. In contrast, in the matched sample of brand owners that opposed other brand owners, the average difference in trademark filings is negative, very small in magnitude (-0.09), and in fact statistically indistinguishable from zero. The pattern looks very similar for the 36-month instead of the 24-month window.

Figure 7 plots the point estimates (and 90\% confidence intervals) on the interaction terms of the following regression $t m_{i \tau}=\alpha+\sum_{\tau=-24}^{\tau=+24} \beta_{s} O_{i \tau \geq 0} \times S Q_{i}+\mu_{i}+\theta_{\tau}+\varepsilon_{i \tau}$ where we define $\tau$ as quarterly intervals. The graph shows that for the \pm 24 months window around the opposition date, trademark filings by brand owners that opposed a squatted trademark jump up immediately after the opposition. The point estimates on the interaction terms that capture the post-opposition period for brand owners opposing squatted trademarks become positive and statistically significant. This offers

\footnotetext{
${ }^{40}$ In fact, there are 1,695 trademarks, but we were unable to obtain the name of the opposing party for 60 trademark filings which we therefore dropped from the sample.

${ }^{41}$ There is a spike in opposed trademarks in 2003 due to the owner of the O'Neill brand Sisco Textiles N.V. that filed 72 oppositions in that year.
} 
clear descriptive evidence that brand owners react differently to squatted trademarks than they do to trademark filings by 'legitimate' applicants, which is consistent with the example of the NBA shown in Figure 2 above.

Table 4 shows the corresponding regression results from estimating Equation (11) (using both a \pm 24 and \pm 36 months window). The first specification only includes the opposition dummy and the dummy interacted with the indicator that shows whether a brand owner opposed a squatter trademark filing. All specifications include time and brand owner dummies. The results indicate that brand owners increase their trademark filings post-opposition only if they opposed a trademark by a squatter. The coefficient in column [1a] implies an increase in trademark filings of .4 following the first opposition of a squatted trademark filing. This is a substantial effect given the mean of 1.107 of the dependent variable. The opposition dummy itself is negative and statistically significant. The coefficient in column [1a] indicates a .44 drop in filings. Table 3 indicated both a positive univariate correlation between opposition to a squatted trademark and trademark filings and a negative correlation between opposition to a trademark by another 'legitimate' brand owner and trademark filings. This means the negative coefficient on the opposition dummy variable once we include a post-opposition $\times$ squatted trademark interaction term picks up the negative correlation between opposition and filings in the matched control sample. A closer look into the data suggests that this negative association is in fact due to the typical opposition behavior of trademark applicants. Generally, applicants appear to first register their brands as trademarks and only then protect their position by opposing potentially conflicting trademark applications. Hence, companies tend to file fewer applications following an opposition because oppositions usually occur once a company has established its trademark portfolio. This reinforces the squatter effect, that is, squatted trademarks trigger a different reaction by brand owners.

In the second column, we add a brand owner's cumulative trademark stock as a covariate to account for the fact that a company's filing behavior depends on the size of its existing trademark portfolio. The coefficient on the stock variable (in log) is positive and statistically significant. While one might expect the number of new filings to be decreasing in the stock of existing filings, the estimates suggest that entities that have been actively trademarking in the past continue to do so. The coefficient on the post-opposition squatter interaction remains positive and statistically significant, whereas the coefficient on the opposition dummy variable on its own is no longer significant in column [2a]. The following four columns split the sample according to the type of applicants, companies, individuals, foreign or domestic. The results show interesting differences between companies and individuals as well as between foreign and domestic entities. The sample that is restricted to foreign brand owners (column 
[5a]) confirms the results of columns [1a] and [2a]. However, we do not find any statistically significant association between the filings of domestic brand owners and the brand owner's first opposition of a squatted trademark (column [6a]). Similarly, we do not find a significant effect for individual applicants; only corporate applicants appear to react to a squatter by filings more trademark applications. This results hold regardless of whether we use a \pm 24 or \pm 36 months window and accord with theoretical model shown in Section 2.

Table 5 shows the results from estimating specifications (12) and (13) which search for evidence on trademark fencing as a response to squatting. The upper panel shows the results from estimating specification (12) using a FE logit model (results are qualitatively the same using a linear probability model). We analyze whether a brand owner's propensity to file in a new Nice class changes for brand owners after the opposition of a squatted trademark. The results of the interaction terms indicate a clear increase in the propensity to file in new Nice classes following the opposition of a squatted trademark, regardless of whether we use a \pm 24 or \pm 36 months window. This means brand owners start branching out their trademark filings in response to squatting to cover classes that they had not previously considered. To investigate this further, the lower panel shows the results for specification (13). The estimates show that brand owners are more likely to file trademarks in areas other than their main business activity. The results, therefore, indicate that brand owners are more likely to file in Nice classes in which they have not filed before and that such filings are more likely to be in classes other than those covering the brand owner's main business activities.

\subsection{Post-registration cancellations}

There are substantially fewer cancellation requests than there are opposition filings. Among all trademarks registered by squatters between 1991-2010, we find 124 requests for cancellation. Among those 124 requests, we have information on the party that made the request only for 100 cancellation requests ${ }^{42}$ Out of the 54 brand owners that filed these 100 requests, only 46 filed trademarks with INAPI at any time during the 1991-2010 period. The regression sample is again slightly smaller because we restrict our attention to the \pm 24 and \pm 36 months windows.

The lower part of Table 3 shows a comparison of average trademark filings preand post-cancellation request for brand owners that take action against a squatted trademark and those that file a cancellation request for a trademark by other 'legiti-

\footnotetext{
${ }^{42}$ We only obtain the names of the parties that filed the cancellation request if the request was decided by INAPI. If cases settle before the judgment is handed down, the information is not revealed.
} 
mate' brand owners. The table shows that in contrast to post-opposition filings, we do not see any statistically significant increase in filings by brand owners after having filed a cancellation request for the first time. In fact, we see a small drop in filings; the average number of filings during the 2 years before the first cancellation of a squatted trademark is 4.4 and 4.2 during the two years following the cancellation. This is confirmed by Figure 8 , which plots the point estimates (and $90 \%$ confidence intervals) on the interaction terms of the following regression $t m_{i \tau}=\alpha+\beta_{C}+\sum_{\tau=-24}^{\tau=+24} \beta_{s} C_{i \tau \geq 0} \times$ $S Q_{i}+\mu_{i}+\theta_{\tau}+\varepsilon_{i \tau}$ where we define $\tau$ again as quarterly intervals. The graph shows that there is no significant change in trademark filing behavior after a cancellation request has been filed.

Table 6 shows the corresponding regression results. When we look at the results for the \pm 24 months window, we do not see any statistically significant coefficients on the squatter post-cancellation interaction term regardless of the specification chosen ${ }^{43}$ The post-cancellation dummy on its own is negative and statistically significant only in columns [2b] and [3b]. The coefficient on the trademark stock in contrast is still positive and statistically significant. The result in column [1b] indicates a negative effect on post-cancellation filings by brand owners attempting to remove squatted trademarks from the register - but the effect is not robust to including the trademark stock.

In combination, the various results on potential changes in trademark filing behavior following the first filing of a cancellation request offer little robust evidence to suggest any significant change in trademark filings by brand owners following the cancellation of a registered squatter trademark. That said, we cannot rule out that the lack of statistical evidence is due to the low number of observations available for our regressions (43 brand owners that attempted to cancel squatted trademarks).

\section{Conclusion}

The main economic justification for the trademark system is that trademarks help to solve the information asymmetry between sellers and buyers. Trademarks are used by companies as a signal to consumers that a product or service is of a certain and consistent quality. This helps consumers reduce their search costs and companies can charge a higher price. Landes and Posner (1987) argue that this ability to charge a higher price provides incentives for companies to invest in the quality and consistency of their products and services. This creates a self-enforcing mechanism: consumer search costs are lowered because trademarks provide credible signals for quality and

\footnotetext{
${ }^{43}$ Note that due to the small number of brand owners filing a cancellation request for a squatted trademark, we include more than one control for each 'treated' brand owner.
} 
companies invest in ensuring their products maintain a given quality because they can charge higher prices to consumers thanks to their ability to signal. It is clear from the discussion of the squatter business model above that squatters who "steal identities or masquerade as people they are not" (Boldrin and Levine, 2008: 8) obstruct this fundamental function of the trademark system.

In practice, identifying squatters is far from trivial. In this paper, we propose an algorithm that identifies trademark squatters in the trademark register based on a combination of ten criteria. The combination of these criteria allows us to attach a single score to each applicant which offers a measure of the likelihood that a given applicant pursues a squatter business model. It is important to highlight that this algorithm identifies applicants that overwhelmingly, if not exclusively, squat trademarks. This omits companies that legitimately own and use trademarked brands but in addition use squatted trademarks for possibly anti-competitive reasons ${ }^{44}$ An important extension of our work will be to shed more light on the combined use of 'legitimate' and squatted trademarks by companies in particular with a view to investigating anticompetitive conduct based on squatted trademarks.

From a legal perspective, and in analogy to patents enforced by patent trolls (Schwartz and Kesan, 2012), the crucial issue is whether trademark squatters are able to enforce legal rights that they should not have been able to register in the first place. Given the systematic nature of squatting uncovered by our analysis, the outcomes of opposition and cancellation actions involving squatted trademarks, it appears safe to say that successful squatting is on average not the outcome of systematic mistakes made by the trademark office. Our theoretical model suggests that squatting is not the outcome of systematic mistakes by brand owners either; brand owners may rationally leave room for squatters. Instead, a large number of legal provisions and institutional design choices determine the success prospects of squatters - including the criteria used to assess whether trademarks qualify as well known, the kind and extent of substantive examination an office engages in, to what degree the applicant is required to prove use before an office registers a trademark, and the details of opposition and cancellation procedures.

\footnotetext{
${ }^{44}$ For example, in a recent antitrust case, Chile's main beer producer, CCU, was found to have obstructed competition by having registered a large number of its mostly foreign competitors' trademarks (see Tribunal de Defensa de la libre Competencia case No C-263-13).
} 


\section{References}

[1] Abud, M.J., C. Fink, B.H. Hall, and C. Helmers (2013): 'The Use of Intellectual Property in Chile,' WIPO Working Paper No. 11.

[2] Ai C. and E. C. Norton (2003): 'Interaction terms in logit and probit models,' Economics Letters, Vol. 80, pp. 123-129.

[3] Boldrin M. and D. K. Levine (2008): 'Against Intellectual Monopoly,' Cambrige University Press.

[4] Dixit A. K. and R. S. Pindyck (1994): 'Investment Under Uncertainty,' Princenton University Press.

[5] Cabral L. M. B. (2000): 'Stretching firm and Brand Reputation,' Rand Journal of Economics, Vol 31(4), pp. 658-673.

[6] Jaffe, A. (1986): 'Technological Opportunity and Spillovers of R\&D: Evidence from Firms Patents, Profits, and Market Value,' American Economic Review, 76(5), pp. 9841001.

[7] Landes W. M. and R. A. Posner (1987): 'Trade mark Law: An Economic Perspective,' Journal of Law and Economics, Vol. 30, pp. 265-309.

[8] Lehmann E. (1966): 'Some concepts of Dependence,' The Annals of Mathematical Statistics, Vol. 37, pp. 1137-1153.

[9] Muthoo A. (1999): 'Bargaining Theory with Applications,' Cambridge University Press.

[10] Pepall L.M. and D.J. Richards (2002): 'The simple economics of brand stretching,' Journal of Business, Vol. 75, pp. 535-552.

[11] Schwartz D. L. and J. P. Kesan (2012): 'Analyzing the Role of Non-Practicing Entities in the Patent System,' Illinois Public Law and Legal Theory Research Paper 13-01.

[12] Telser L. G (1980): 'A Theory of Self Enforcement Agreements,' Journal of Business, Vol. 53, pp. 27-44.

[13] Wernerfelt B. (1988): 'Umbrella Branding as a Signal of New Product Quality: An Example of Signalling by Posting a Bond,' RAND Journal of Economics, Vol. 19, pp. 458466. 
Figure 3: Squatter trademark filings 1991-2010

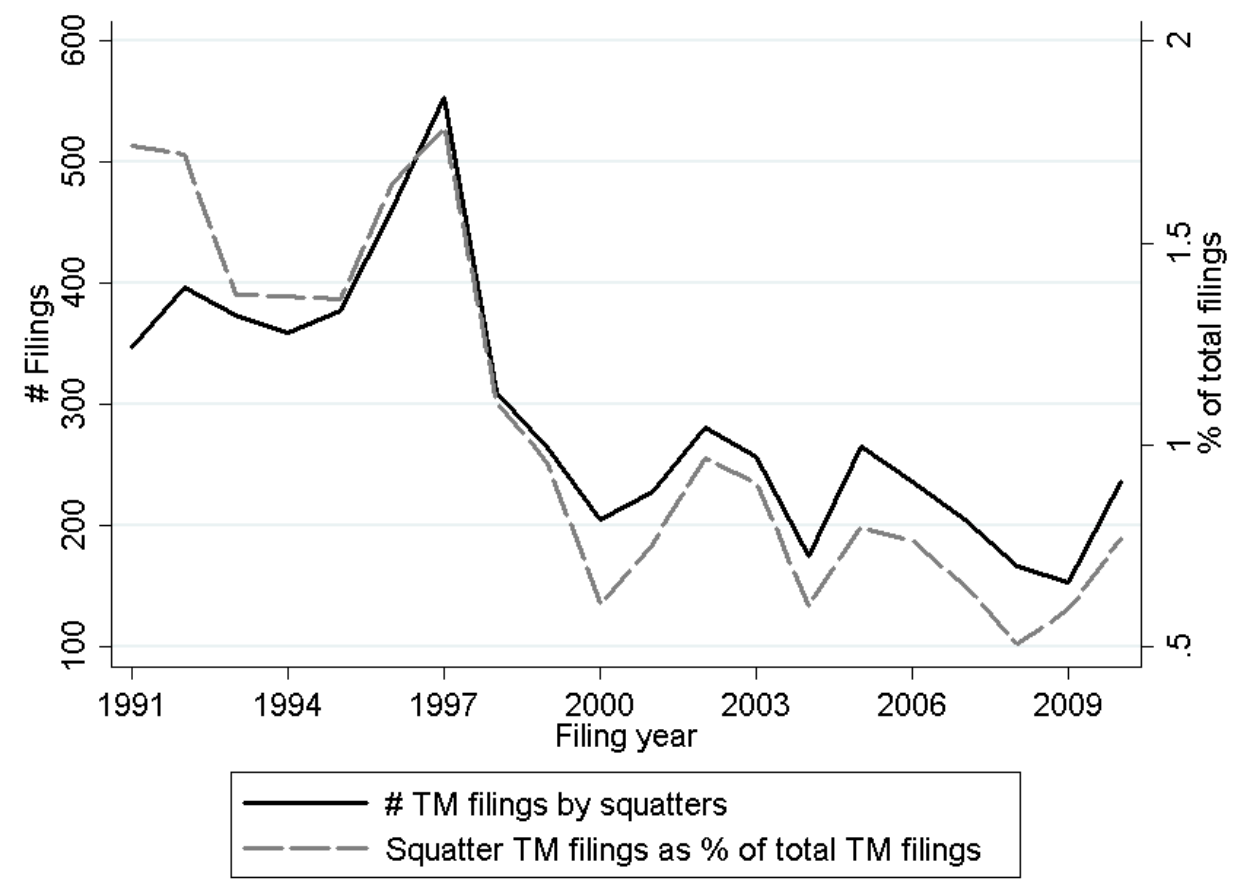


Figure 4: Trademark filings by economic activity (1991-2010)

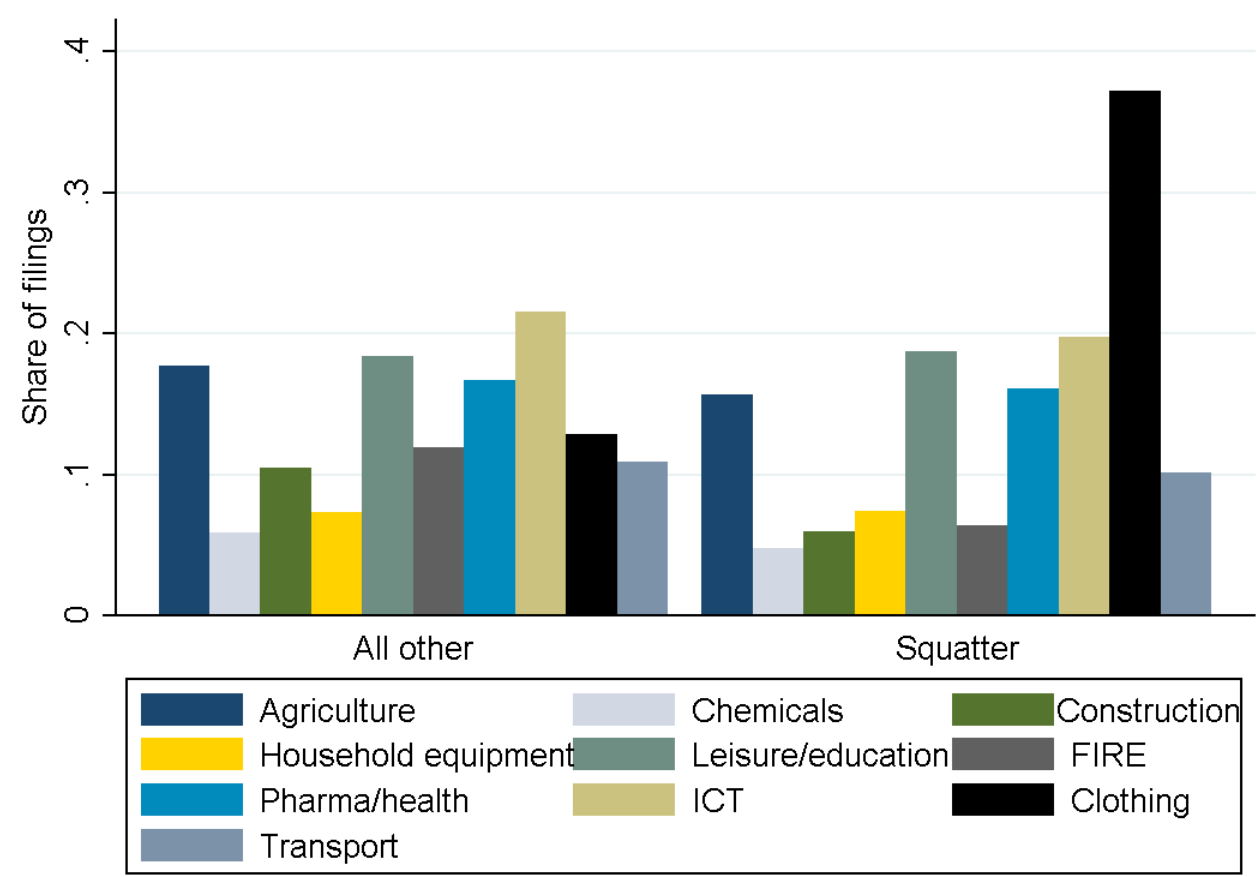

Notes: Class groups were defined by Edital (2011): Agricultural products and services: 29, 30, 31, 32, 33, 43; Chemicals: 1, 2, 4; Construction, Infrastructure: 6, 17, 19, 37, 40; Household equipment: 8, 11, 20, 21; Leisure, Education, Training: 13, 15, 16, 28, 41; Management, Communications, Real estate and Financial services: 35, 36; Pharmaceuticals, Health, Cosmetics: 3, 5, 10, 44; Scientific research, Information and Communication technology: 9, 38, 42, 45; Textiles - Clothing and Accessories: 14, 18, 22, 23, 24, 25, 26, 27, 34; Transportation and Logistics: 7, 12, 39. 
Figure 5: Number of oppositions of squatter trademark filings and opposition parties 1991-2010

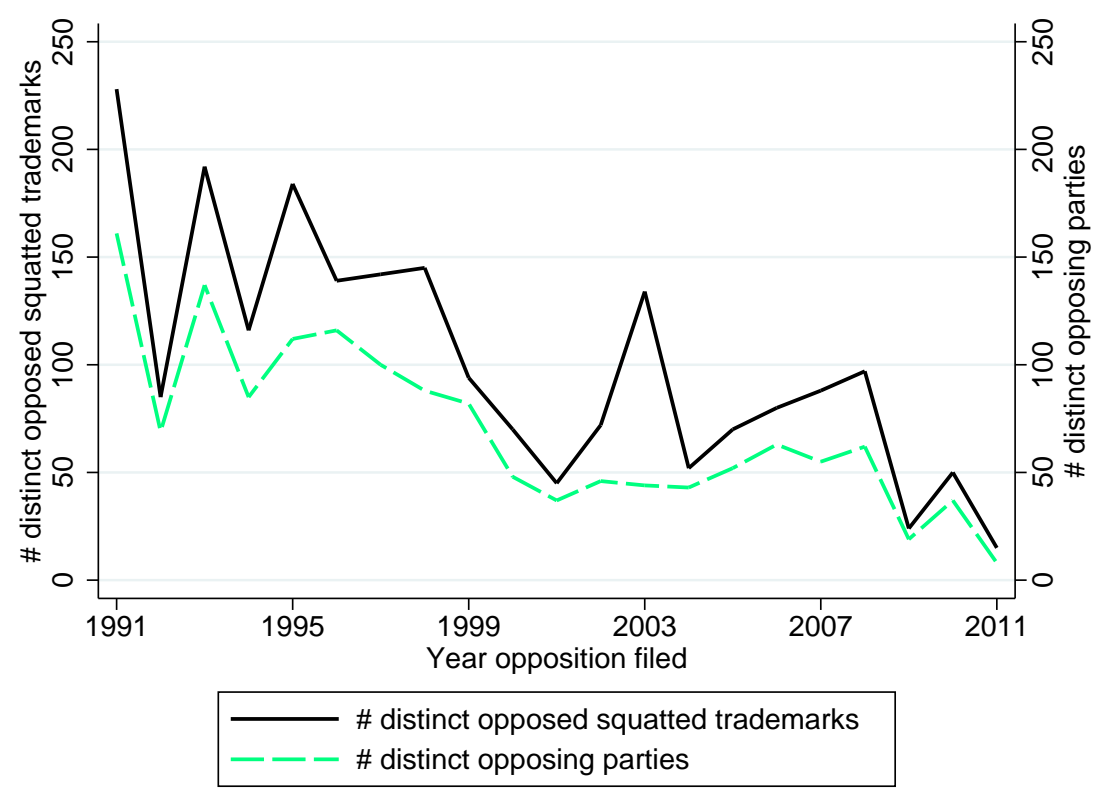

Figure 6: Number of cancellation requests of registered squatter trademark and requesting parties 1991-2010

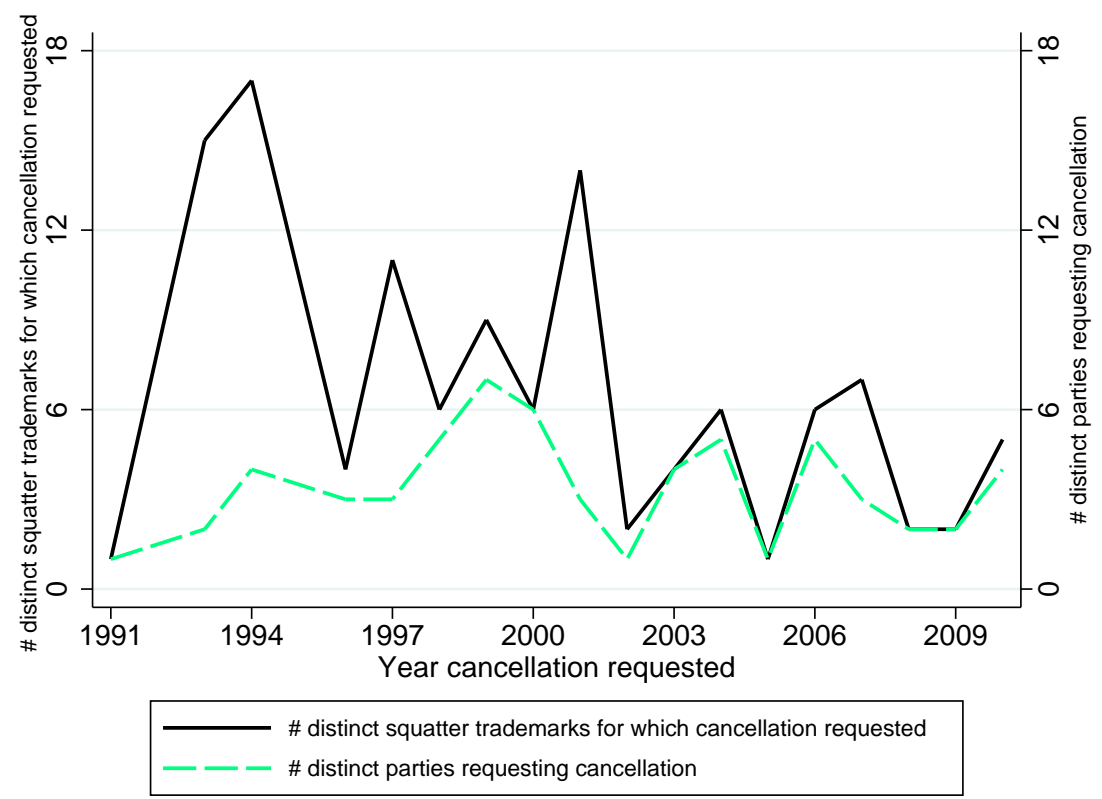


Figure 7: Post-opposition trademark filing behavior of owners of squatted trademarks vs control group 1991-2010

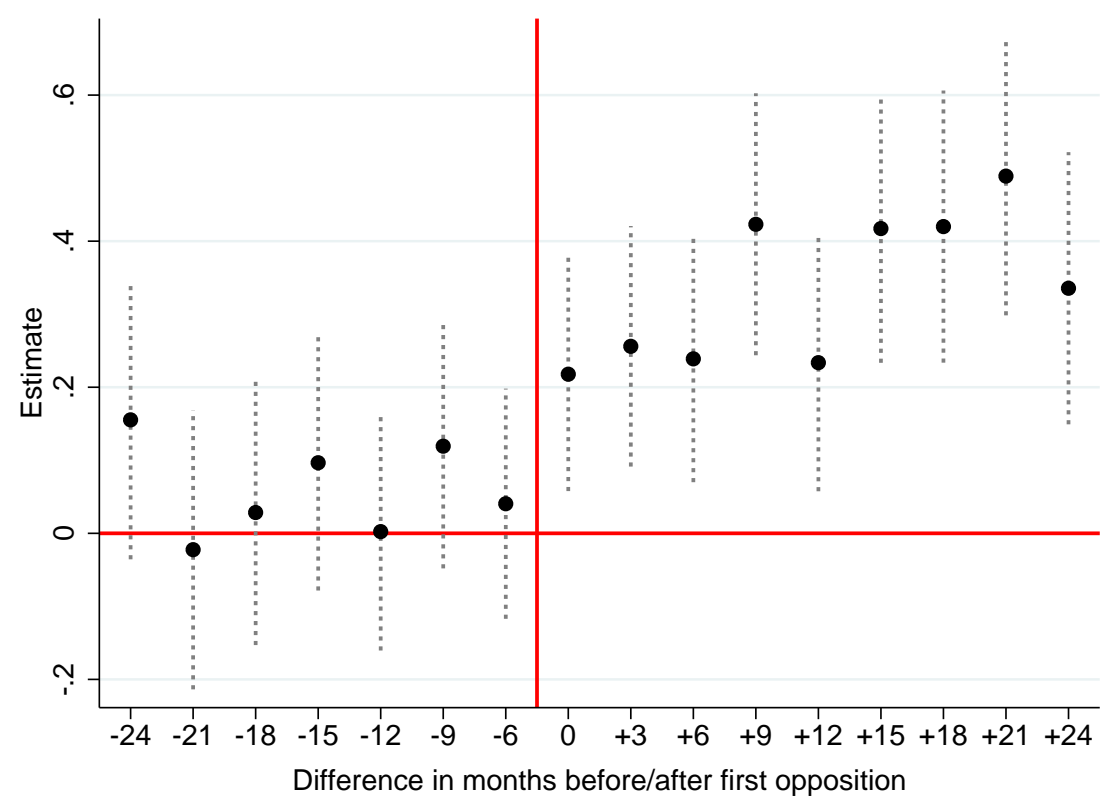

Notes: Plots point estimates and $90 \%$ confidence intervals from the following negative binomial regression $t m_{i \tau}=\alpha+\sum_{\tau=-24}^{\tau=-24} \beta_{s} O_{i \tau=0} \times S Q_{i}+\mu_{i}+\theta_{\tau}+\varepsilon_{i \tau}$ where $t m_{i t}$ denotes filings by brand owner $i$ in year $\tau$ (including brand owners opposing a squatted trademark filing as well as brand owners opposing a filing by a 'legitimate' applicant), $\mu_{i}$ are applicant-level fixed effects and $\theta_{\tau}$ is a time trend. $O_{i \tau=0}$ is a dummy variably which is equal to one once a brand owner opposed for the first time a trademark. $S Q_{i}$ identifies brand owners that opposed a squatted trademark. Opposition date defined by publication date of opposed trademark where opposition represents 1st opposition by brand owner to squatted trademark or 1st opposition by matched control during the sample period. Control group matched based on characteristics (filing year, trademark type, trademark use, existence of priority filing, Nice classes) of squatted trademark. Sample consists of 977 brand owners opposing squatted trademarks and 977 matched control brand owners opposing trademark filings by other 'legitimate' brand owners. 
Figure 8: Post-cancellation trademark filing behavior of owners of squatted trademarks vs control group 1991-2010

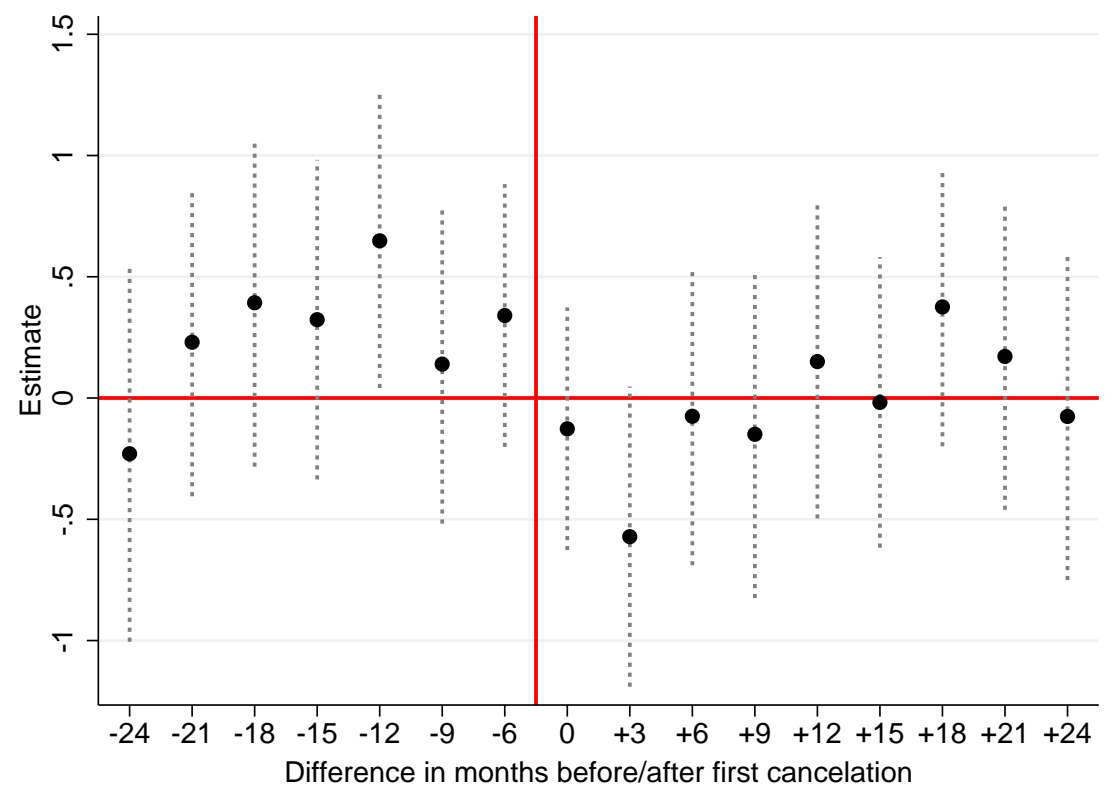

Notes: Plots point estimates and $90 \%$ confidence intervals from the following negative binomial regression $\mathrm{tm}_{i \tau}=\alpha+\beta_{C}+\sum_{\tau=-24}^{\tau=-24} \beta_{s} C_{i \tau=0} \times S Q_{i}+\mu_{i}+\theta_{\tau}+\varepsilon_{i \tau}$ where $\mathrm{tm}_{i t}$ denotes filings by brand owner $i$ in year $\tau$ (including brand owners requesting the cancellation of a squatted trademark filing as well as brand owners requesting the cancellation of a trademark by a 'legitimate' applicant), $\mu_{i}$ are applicant-level fixed effects and $\theta_{\tau}$ is a time trend. $C_{i \tau=0}$ is a dummy variably which is equal to one once a brand owner filed a cancellation request for the first time a trademark. $S Q_{i}$ identifies brand owners that requested the cancellation of a squatted trademark. The date is defined by date the cancellation request was made where cancellation represents the 1st cancellation request by brand owner of a registered squatted trademark or 1st cancellation request by control during the sample period. Control group matched based on characteristics (filing year, trademark type, trademark use, existence of priority filing, Nice classes) of squatted trademark. Sample consists of 41 brand owners opposing squatted trademarks and 117 control brand owners requesting the cancellation of registered trademarks by other 'legitimate' brand owners. 
Table 1: Comparison of squatter characteristics

\begin{tabular}{|c|c|c|c|c|c|c|c|}
\hline & \multicolumn{2}{|c|}{ MEAN } & \multicolumn{2}{|c|}{ STD. DEV. } & \multirow{2}{*}{$\begin{array}{l}\text { T-TEST } \\
\text { difference }\end{array}$} & \multicolumn{2}{|c|}{ \# OBS. } \\
\hline & Squatter & All other & Squatter & All other & & Squatter & All othe \\
\hline \multicolumn{8}{|l|}{ COMPANIES } \\
\hline Opposition & 0.321 & 0.170 & 0.029 & 0.001 & -4.49 & 88 & 72,982 \\
\hline Invalidation & 0.061 & 0.007 & 0.187 & 0.076 & -4.976 & 50 & 43,978 \\
\hline Rejection & 0.649 & 0.306 & 0.041 & 0.002 & -7.538 & 84 & 56,965 \\
\hline Simultaneous filings & 0.684 & 0.646 & 0.162 & 0.158 & -2.008 & 70 & 22,969 \\
\hline Class diversity & 0.497 & 0.621 & 0.342 & 0.298 & 3.363 & 66 & 14,543 \\
\hline Priority & 0.002 & 0.029 & 0.015 & 0.151 & 1.73 & 88 & 72,982 \\
\hline Type of use & 0.104 & 0.063 & 0.196 & 0.202 & -1.865 & 88 & 72,982 \\
\hline Product & 0.856 & 0.581 & 0.271 & 0.445 & -5.804 & 88 & 72,982 \\
\hline Top brand & 0.057 & 0.003 & 0.233 & 0.053 & -9.439 & 88 & 72,982 \\
\hline \multicolumn{8}{|l|}{ INDIVIDUALS } \\
\hline Opposition & 0.383 & 0.148 & 0.017 & 0.001 & -14.140 & 344 & 58,566 \\
\hline Invalidation & 0.103 & 0.011 & 0.252 & 0.098 & -13.108 & 210 & 25,164 \\
\hline Rejection & 0.681 & 0.448 & 0.338 & 0.462 & -9.281 & 338 & 40,120 \\
\hline Simultaneous filings & 0.611 & 0.596 & 0.157 & 0.144 & -1.655 & 268 & 11,140 \\
\hline Class diversity & 0.665 & 0.651 & 0.299 & 0.293 & -0.727 & 223 & 6,389 \\
\hline Priority & 0.002 & 0.003 & 0.028 & 0.052 & 0.439 & 344 & 58,566 \\
\hline Type of use & 0.125 & 0.097 & 0.221 & 0.256 & -2.026 & 344 & 58,566 \\
\hline Product & 0.710 & 0.464 & 0.335 & 0.459 & -9.895 & 344 & 58,566 \\
\hline Top brand & 0.174 & 0.005 & 0.38 & 0.074 & -39.204 & 344 & 58,566 \\
\hline
\end{tabular}

Notes: * Differences in bold are statistically significant at $<10 \%$ level. 
Table 2: Predicting squatter status

\begin{tabular}{|c|c|c|c|c|c|c|}
\hline \multirow[b]{3}{*}{ Company $(0 / 1)$} & \multicolumn{3}{|c|}{ OLS } & \multicolumn{3}{|c|}{ LOGIT } \\
\hline & Coefficient & & Std. error & Coefficient & & Std. error \\
\hline & -0.005 & $* * *$ & 0.0004 & -1.768 & $* * *$ & 0.128 \\
\hline Opposition & 0.005 & $* * *$ & 0.0005 & 1.552 & $* * *$ & 0.127 \\
\hline Invalidation & 0.037 & $* * *$ & 0.008 & 1.834 & $* * *$ & 0.253 \\
\hline Rejection & 0.005 & $* * *$ & 0.0004 & 1.580 & $* * *$ & 0.112 \\
\hline Simultaneous filings & 0.006 & $* * *$ & 0.001 & 2.326 & $* * *$ & 0.213 \\
\hline Class diversity & 0.008 & $* * *$ & 0.001 & 1.129 & $* * *$ & 0.183 \\
\hline Priority & -0.002 & $* * *$ & 0.0004 & -2.146 & & 1.443 \\
\hline Type of use & -0.001 & & 0.0007 & -0.410 & * & 0.238 \\
\hline Product & 0.003 & $* * *$ & 0.0003 & 1.137 & $* * *$ & 0.150 \\
\hline Top brand $(0 / 1)$ & 0.096 & $* * *$ & 0.013 & 1.840 & $* * *$ & 0.169 \\
\hline \# Obs. $(\#=1)$ & & & 132,2 & $(432)$ & & \\
\hline
\end{tabular}

Notes: Robust standard errors. We indicate statistical significance at the $10 \%, 5 \%$ and $1 \%$ level using $*, * *$ and $* * *$ respectively. 
Table 3: Comparison of trademark filings between brand owner vs matched control group

\begin{tabular}{|c|c|c|c|c|c|c|}
\hline & $\begin{array}{r}\mathrm{Br} \\
\text { (agains }\end{array}$ & $\begin{array}{l}\text { nd owr } \\
\text { squatt }\end{array}$ & $\begin{array}{l}\text { er } \\
\text { d TM) }\end{array}$ & $\overline{\text { Matc }}$ & ed TM & wner \\
\hline & Before & After & T-test & Before & After & T-test \\
\hline pre/post-opp & & & & & & \\
\hline \pm 24 months & & & & & & \\
\hline TM filings & 1.251 & 1.583 & -2.199 & 0.835 & 0.739 & 1.528 \\
\hline \pm 36 months & & & & & & \\
\hline TM filings & 1.147 & 1.504 & -3.179 & 0.783 & 0.679 & 1.969 \\
\hline pre/post-can & & & & & & \\
\hline \pm 24 months & & & & & & \\
\hline TM filings & 4.434 & 4.222 & 0.136 & 2.562 & 3.387 & -1.361 \\
\hline \pm 36 months & & & & & & \\
\hline TM filings & 4.145 & 3.848 & 0.247 & 2.097 & 3.164 & -2.248 \\
\hline
\end{tabular}

Notes: Opposition date defined by publication date of opposed trademark where opposition represents 1st opposition by brand owner to squatted trademark or 1st opposition by matched control during the sample period. Cancellation date defined by date cancellation request filed where cancellation represents 1st cancellation by brand owner to squatted trademark or 1st cancellation by control brand owner during the sample period. Control groups for opposition and cancellation matched based on characteristics (filing year, trademark type, trademark use, existence of priority filing, Nice classes) of squatted trademark. 
Table 4: Brand owner vs matched control group pre/post-opposition (1st opposition) filing behavior

\begin{tabular}{|c|c|c|c|c|c|c|}
\hline \multirow{3}{*}{$+/-24$ months } & \multicolumn{2}{|c|}{ All } & \multirow{3}{*}{$\begin{array}{c}\text { Companies } \\
{[3 a]}\end{array}$} & \multirow{3}{*}{$\begin{array}{c}\text { Individuals } \\
{[4 a]}\end{array}$} & \multirow{3}{*}{$\begin{array}{c}\text { Foreign } \\
{[5 a]}\end{array}$} & \multirow{3}{*}{$\begin{array}{c}\text { Domestic } \\
6 \mathrm{a}]\end{array}$} \\
\hline & & & & & & \\
\hline & [1a] & [2a] & & & & \\
\hline Post-opp. $\times$ Squatted TM & $\begin{array}{l}0.405^{* *} \\
(0.179)\end{array}$ & $\begin{array}{l}0.404^{* *} \\
(0.180)\end{array}$ & $\begin{array}{l}0.446^{* *} \\
(0.223)\end{array}$ & $\begin{array}{c}0.166 \\
(0.118)\end{array}$ & $\begin{array}{l}0.615^{*} \\
(0.364)\end{array}$ & $\begin{array}{c}0.208 \\
(0.156)\end{array}$ \\
\hline Post-opposition & $\begin{array}{c}-0.443^{* * *} \\
(0.156)\end{array}$ & $\begin{array}{l}-0.295 \\
(0.199)\end{array}$ & $\begin{array}{l}-0.361 \\
(0.251)\end{array}$ & $\begin{array}{c}-0.676^{* * *} \\
(0.142)\end{array}$ & $\begin{array}{l}-0.482 \\
(0.342)\end{array}$ & $\begin{array}{l}-0.182 \\
(0.187)\end{array}$ \\
\hline $\ln$ (TM stock) & & $\begin{array}{c}1.259^{* * *} \\
(0.117)\end{array}$ & $\begin{array}{c}1.369^{* * *} \\
(0.143)\end{array}$ & $\begin{array}{c}0.795^{* * *} \\
(0.065)\end{array}$ & $\begin{array}{c}1.497^{* * *} \\
(0.329)\end{array}$ & $\begin{array}{c}1.169^{* * *} \\
(0.083)\end{array}$ \\
\hline Time dummies & Yes & Yes & Yes & Yes & Yes & Yes \\
\hline Brand/TM owner FE & Yes & Yes & Yes & Yes & Yes & Yes \\
\hline \# Observations & 32,672 & 32,672 & 25,461 & 7,211 & 11,665 & 21,007 \\
\hline Brand owners & 977 & 977 & 801 & 176 & 412 & 565 \\
\hline Control TM owners & 977 & 977 & 722 & 255 & 286 & 691 \\
\hline \multirow[t]{2}{*}{ +/-36 months } & & & & & & \\
\hline & [1b] & {$[2 b]$} & [3b] & {$[4 \mathrm{~b}]$} & [5b] & [6b] \\
\hline Post-opp. $\times$ Squatted TM & $\begin{array}{c}0.396^{* * *} \\
(0.149)\end{array}$ & $\begin{array}{c}0.392^{* * *} \\
(0.150)\end{array}$ & $\begin{array}{l}0.468^{* *} \\
(0.188)\end{array}$ & $\begin{array}{c}0.047 \\
(0.108)\end{array}$ & $\begin{array}{l}0.549^{* *} \\
(0.275)\end{array}$ & $\begin{array}{c}0.226 \\
(0.150)\end{array}$ \\
\hline Post-opposition & $\begin{array}{c}-0.432^{* *} \\
(0.188)\end{array}$ & $\begin{array}{c}-0.855^{* * *} \\
(0.193)\end{array}$ & $\begin{array}{c}-0.923^{* * *} \\
(0.246)\end{array}$ & $\begin{array}{c}0.015 \\
(0.174)\end{array}$ & $\begin{array}{c}-0.927^{* *} \\
(0.367)\end{array}$ & $\begin{array}{c}-0.807^{* * * *} \\
(0.223)\end{array}$ \\
\hline $\ln (\mathrm{TM}$ stock $)$ & & $\begin{array}{c}1.041^{* * *} \\
(0.082)\end{array}$ & $\begin{array}{c}1.122^{* * *} \\
(0.100)\end{array}$ & $\begin{array}{c}0.681^{* * *} \\
(0.062)\end{array}$ & $\begin{array}{c}1.150^{* * *} \\
(0.205)\end{array}$ & $\begin{array}{c}1.012^{* * *} \\
(0.079)\end{array}$ \\
\hline Time dummies & Yes & Yes & Yes & Yes & Yes & Yes \\
\hline Brand/TM owner FE & Yes & Yes & Yes & Yes & Yes & Yes \\
\hline \# Observations & 46,808 & 46,808 & 36,427 & 10,381 & 16,638 & 30,170 \\
\hline Brand owners & 977 & 977 & 801 & 176 & 412 & 565 \\
\hline Control TM owners & 977 & 977 & 722 & 255 & 286 & 691 \\
\hline
\end{tabular}

Notes: OLS FE regression. Dependent variable number of trademark filings by brand owner. Opposition date defined by publication date of opposed trademark where opposition represents 1st opposition by brand owner to squatted trademark or 1st opposition by matched control during the sample period. Control group matched based on characteristics (filing year, trademark type, trademark use, existence of priority filing, Nice classes) of squatted trademark. Robust standard errors clustered at the trademark applicant-level. We indicate statistical significance at the $10 \%, 5 \%$ and $1 \%$ level using $*, * *$ and $* * *$ respectively. 
Table 5: Brand owner vs matched control group pre/post-opposition (1st opposition) trademark fencing behavior

\begin{tabular}{|c|c|c|c|c|}
\hline \multirow{2}{*}{\multicolumn{3}{|c|}{ Propensity to file in new Nice classes }} & \multicolumn{2}{|c|}{$+/ /-36$ months } \\
\hline & & & \multirow[b]{2}{*}{ [3a] } & \multirow[b]{2}{*}[4\mathrm{a}]{} \\
\hline & [1a] & {$[2 \mathrm{a}]$} & & \\
\hline Post-opp. $\times$ Squatted TM & $\begin{array}{c}0.304^{* * *} \\
(0.088)\end{array}$ & $\begin{array}{c}0.359^{* * *} \\
(0.092)\end{array}$ & $\begin{array}{c}0.283^{* * *} \\
(0.077)\end{array}$ & $\begin{array}{c}0.321^{* * *} \\
(0.079)\end{array}$ \\
\hline Post-opposition & $\begin{array}{c}-0.936^{* * *} \\
(0.136)\end{array}$ & $\begin{array}{c}-1.629^{* * *} \\
(0.145)\end{array}$ & $\begin{array}{c}-1.191^{* * *} \\
(0.142)\end{array}$ & $\begin{array}{c}-1.841^{* * *} \\
(0.149)\end{array}$ \\
\hline $\ln (\mathrm{TM}$ stock) & & $\begin{array}{c}1.362^{* * *} \\
(0.079)\end{array}$ & & $\begin{array}{c}1.085^{* * *} \\
(0.058)\end{array}$ \\
\hline Time dummies & Yes & Yes & Yes & Yes \\
\hline Brand/TM owner FE & Yes & Yes & Yes & Yes \\
\hline \# Observations & 16,541 & 16,541 & 26,079 & 26,079 \\
\hline Brand owners & 513 & 513 & 594 & 594 \\
\hline Control TM owners & 480 & 480 & 569 & 569 \\
\hline \multicolumn{5}{|c|}{ Propensity to file in areas other than main business } \\
\hline & {$[1 b]$} & {$[2 b]$} & {$[3 b]$} & {$[4 b]$} \\
\hline Post-opp. $\times$ Squatted TM & $\begin{array}{c}0.285^{* * *} \\
(0.092)\end{array}$ & $\begin{array}{c}0.323^{* * *} \\
(0.097)\end{array}$ & $\begin{array}{c}0.331^{* * *} \\
(0.079)\end{array}$ & $\begin{array}{c}0.375^{* * *} \\
(0.084)\end{array}$ \\
\hline Post-opposition & $\begin{array}{c}-0.597^{* * *} \\
(0.141)\end{array}$ & $\begin{array}{c}-1.362^{* * *} \\
(0.151)\end{array}$ & $\begin{array}{c}-0.665^{* * *} \\
(0.141)\end{array}$ & $\begin{array}{c}-1.503^{* * *} \\
(0.149)\end{array}$ \\
\hline $\ln (\mathrm{TM}$ stock) & & $\begin{array}{c}1.776^{* * *} \\
(0.101)\end{array}$ & & $\begin{array}{c}1.626^{* * *} \\
(0.077)\end{array}$ \\
\hline Time dummies & Yes & Yes & Yes & Yes \\
\hline Brand/TM owner FE & Yes & Yes & Yes & Yes \\
\hline \# Observations & 14,210 & 14,210 & 22,938 & 22,938 \\
\hline Brand owners & 438 & 438 & 487 & 487 \\
\hline Control TM owners & 411 & 411 & 466 & 466 \\
\hline
\end{tabular}

Notes: FE logit regressions. Upper panel: binary dependent variable $=1$ if trademark filed in a Nice class in which brand owner had not filed previously. Lower panel: binary dependent variable $=1$ if trademark filed in an economic activity area other than the main economic activity of the brand owner. Opposition date defined by publication date of opposed trademark where opposition represents 1st opposition by brand owner to squatted trademark or 1st opposition by matched control during the sample period. Control group matched based on characteristics (filing year, trademark type, trademark use, existence of priority filing, Nice classes) of squatted trademark. We indicate statistical significance at the $10 \%, 5 \%$ and $1 \%$ level using $*, * *$ and $* * *$ respectively. 
Table 6: Brand owner vs matched control group pre/post-cancellation (1st cancellation) filing behavior

\begin{tabular}{|c|c|c|c|c|}
\hline \multirow[b]{2}{*}{$+/-24$ months } & \multicolumn{2}{|c|}{ All } & \multirow[t]{2}{*}{ Companies } & \multirow[t]{2}{*}{ Foreign } \\
\hline & & & & \\
\hline & [1a] & {$[2 \mathrm{a}]$} & [3a] & [4a] \\
\hline Post-cancel. $\times$ Squatted TM & $\begin{array}{l}-1.135 \\
(0.740)\end{array}$ & $\begin{array}{l}-0.251 \\
(0.809)\end{array}$ & $\begin{array}{l}-0.248 \\
(0.910)\end{array}$ & $\begin{array}{c}0.707 \\
(0.698)\end{array}$ \\
\hline Post-cancellation & $\begin{array}{c}0.170 \\
(0.767)\end{array}$ & $\begin{array}{c}0.186 \\
(0.813)\end{array}$ & $\begin{array}{c}0.220 \\
(0.922)\end{array}$ & $\begin{array}{l}-0.541 \\
(0.585)\end{array}$ \\
\hline $\ln$ (TM stock) & & $\begin{array}{c}3.636^{* * *} \\
(0.653)\end{array}$ & $\begin{array}{c}3.772^{* * *} \\
(0.689)\end{array}$ & $\begin{array}{c}3.051^{* * *} \\
(0.815)\end{array}$ \\
\hline Time dummies & Yes & Yes & Yes & Yes \\
\hline Brand/TM owner FE & Yes & Yes & Yes & Yes \\
\hline \# Observations & 2,876 & 2,876 & 2,570 & 1,978 \\
\hline Brand owners & 43 & 43 & 41 & 36 \\
\hline Control TM owners & 127 & 127 & 111 & 81 \\
\hline \multirow[t]{2}{*}{$+/-36$ months } & & & & \\
\hline & {$[1 b]$} & {$[2 \mathrm{~b}]$} & [3b] & {$[4 \mathrm{~b}]$} \\
\hline Post-cancel $\times$ Squatted TM & $\begin{array}{c}-1.509^{* *} \\
(0.712)\end{array}$ & $\begin{array}{l}-0.580 \\
(0.685)\end{array}$ & $\begin{array}{l}-0.631 \\
(0.752)\end{array}$ & $\begin{array}{l}-0.016 \\
(0.574)\end{array}$ \\
\hline Post-cancellation & $\begin{array}{c}-0.735 \\
(0.715)\end{array}$ & $\begin{array}{c}-3.710^{* * *} \\
(0.953)\end{array}$ & $\begin{array}{c}-3.927^{* * *} \\
(1.036)\end{array}$ & $\begin{array}{l}-0.265 \\
(0.607)\end{array}$ \\
\hline $\ln (\mathrm{TM}$ stock) & & $\begin{array}{c}3.839^{* * *} \\
(0.933)\end{array}$ & $\begin{array}{c}4.005^{* * *} \\
(0.970)\end{array}$ & $\begin{array}{c}2.671^{* * *} \\
(0.671)\end{array}$ \\
\hline Time dummies & Yes & Yes & Yes & Yes \\
\hline Brand/TM owner FE & Yes & Yes & Yes & Yes \\
\hline \# Observations & 4,177 & 4,177 & 3,735 & 2,885 \\
\hline Brand owners & 43 & 43 & 41 & 36 \\
\hline Control TM owners & 127 & 127 & 111 & 81 \\
\hline
\end{tabular}

Notes: OLS FE regression. Dependent variable number of trademark filings by brand owner. Cancellation date defined by date cancellation request filed where cancellation represents 1st cancellation by brand owner to squatted trademark or 1st cancellation by control brand owner during the sample period. Control group matched based on characteristics (filing year, trademark type, trademark use, existence of priority filing, Nice classes) of squatted trademark. Robust standard errors clustered at the trademark applicant-level. We indicate statistical significance at the $10 \%, 5 \%$ and $1 \%$ level using $*, * *$ and $* * *$ respectively. 


\section{A Appendix: Model extensions and proofs of propositions}

\section{A.1 Model extension: Informational Advantadge}

For simplicity, in the basic model presented in Section 2.1 we have assumed that the squatter knows at date 1 whether the state is good or bad. We now extend our model to allow for a less extreme form of informational advantadge. For that, let $\omega$ denote the state of the market and $\mathrm{G}$ (B) to represent the good (bad) state; i.e., $\omega \in\{G, B\}$. The squatter's information comes in the form of a symmetric binary signal $s$ with precision $q$ :

$$
\operatorname{Pr}(s=\omega \mid \omega)=q,
$$

where $q>0.545$ To simplify our discussion, we assume both an expensive cancellation system and that $c_{1}=c_{2}=c$.

The squatter must now decide whether to file an application or not after observing signal $s$. Let us assume that he finds it profitable to file an application if, and only if, he receives a good signal. More formally, let us assume that the following inequality holds:

$$
\mu^{-} \lambda n_{2}^{*}<c<\mu^{+} \lambda n_{2}^{*},
$$

where $\mu^{-} \equiv \operatorname{Pr}(\omega=G \mid s=B)$ and $\mu^{+} \equiv \operatorname{Pr}(\omega=G \mid s=G)$, and by Bayes's rule

$$
\mu^{-}=\frac{(1-q) \mu}{(1-q) \mu+q(1-\mu)}, \quad \text { and } \quad \mu^{+}=\frac{q \mu}{q \mu+(1-q)(1-\mu)} .
$$

Note that as $q$ becomes arbitrarily close to one, the squatter knows, as in our basic model, the state of the market with certainty. It should then be clear that all our previous results still hold, although the equilibrium expressions are much more involved.

\section{A.2 Model extension: Cheap Cancellation System}

Under a cheap cancellation system, if negotiations end up in disagreement the brand owner will find it profitable to initiate a cancellation procedure. So, the reservation or disagreement payoffs for the negotiations are given by $d=(\tilde{h}-k, 0)$. Now the price $p$ at which the trademark will be sold to the brand onwer solves:

$$
\max _{p}(h-p-\tilde{h}+k)^{1-\tau}(p)^{\tau}
$$

\footnotetext{
${ }^{45}$ If $q=0.5$ the signal would not be informative, i.e., agent 2 would still believe, after receiving the signal, that the state is good with probability equal to $\mu$.
} 
where, as before, $\tau \in(0,1)$ is the relative bargaining power of the squatter. The unique solution to the above problem is:

$$
p^{*}=\tau(h-\tilde{h}+k),
$$

and hence payoffs are:

$$
\begin{aligned}
& n_{1}=h-p^{*}=(1-\tau) h+\tau(\tilde{h}-k), \\
& n_{2}=p^{*}=\tau(h-\tilde{h}+k) .
\end{aligned}
$$

Intuitively, as the reservation payoff of the brand owner is strictly positive under this system, the price at which the trademark will be traded is smaller than the equilibrium price under an expensive cancellation system. It should then be clear that all our results hold in this case with the only difference that now the smallest cost that makes the net value of waiting positive is

$$
c_{1}^{\dagger} \equiv \frac{\mu \lambda \xi}{\mu \lambda \xi+(1-\mu)} \tau(\tilde{h}-k)<c_{1}^{*},
$$

and the largest cost that makes squatting profitable is

$$
c_{2}^{\dagger} \equiv \lambda \tau(h-\tilde{h}+k)<c_{2}^{*}
$$

Hence, under a cheap cancellation system, the squatting active equilibrium will more likely to take place for smaller values of $c$.

\section{A.3 Model extension: Opposition Stage}

Registering a trademark in Chile involves three stages: (i) the filing of an application, (ii) its publication in the gazette and: (iii) a substantive examination. Once published in the gazette, the application can be opposed. If an application is either not opposed or the opposition is rejected, it proceeds to the substantive examination. If an application successfully passes the substantive examination, the trademark is registered.

Here we discuss how the possibility of a pre-grant opposition affects our main results. For that, we modify our original game along the following lines. We allow the brand owner to file an opposition after the squatter's application has been published but before the trademark is registered. Filing an opposition is a costly and uncertain procedure (see Section 3.1.2). Let $\rho \in(0,1)$ be the probability that an application survives opposition and let $\kappa>0$ be the cost of the opposition to the brand owner.

Clearly the results of Section 2.5.1 still go through. Hence, we need to consider the sub- 
game that follows when the brand owner does not register the brand at date 0 and the squatter files an application at date 1. Will the brand owner file an opposition?

To answer this question, let us assume that the probability $\lambda$ of registering the trademark is not affected by an unsuccessful opposition ${ }^{46}$ We first obtain the expected payoff of filing an opposition. On the one hand, the brand owner will obtain a payoff equal to $h-c_{1}$ if he manages to register the brand at date 2. This event occurs when either: (i) the opposition is a success; or: (ii) the opposition is unsuccessful but the squatter's application is rejected by the trademark office. Thus, the total probability of this event is:

$$
(1-\rho)+\rho(1-\lambda)
$$

On the other hand, the brand owner will get a payoff equal to $n_{1}$ when the opposition is unsuccessful and the squatter's application is accepted by the trademark office. The probability of this event is:

$$
\rho \lambda .
$$

Hence the expected payoff of filing an opposition is:

$$
\pi_{\mathrm{o}}=[(1-\rho)+\rho(1-\lambda)]\left(h-c_{1}\right)+\rho \lambda n_{1}-\kappa .
$$

Of course, the brand owner can refrain from filing an opposition. What is then his expected payoff? Now he gets a payoff equal to $h-c_{1}$ if, and only if, the squatter's application is rejected by the trademark office; an event that takes place with probability $1-\lambda$. With probability $\lambda$, the application is granted and he receives a payoff equal to $n_{1}$. Thus his expected payoff from refraining to file an opposition is

$$
(1-\lambda)\left(h-c_{1}\right)+\lambda n_{1}
$$

Using (5), it follows that filing an opposition is profitable if, and only if:

$$
\lambda(1-\rho)\left(\tau h-c_{1}\right) \geq \kappa .
$$

The intuition is simple. Since it costs $c_{1}$ to the brand owner to register the brand but he has to pay $\tau h$ to the squatter, one can view $\lambda(1-\rho)\left(\tau h-c_{1}\right)$ as the expected savings due to the opposition. In summary, we have:

Proposition 9 (Equilibrium oppositions). The brand owner will file an opposition if, and

\footnotetext{
${ }^{46}$ Relaxing this independence assumption does not affect our results but it makes our calculations less clear.
} 
only if:

$$
\kappa \leq \kappa^{*} \equiv \lambda(1-\rho)\left(\tau h-c_{1}\right) .
$$

Thus oppositions are more likely to be filed when both the squatter bargaining power $\tau$ and the probability of successfully registering a trademark $\lambda$ are high.

An important aspect is whether a squatting active equilibrium exists in the presence of an opposition stage. First, observe that if $\kappa>\kappa^{*}$, the brand owner will not file an opposition and therefore all our previous results remain unchanged. So let us consider the case in which the brand owner files an opposition, that is the situation in which $\kappa \leq \kappa^{*}$.

We begin by taking the perspective of the squatter at date 1 when the state is good. The payoff that he obtains by filing a trademark application is now:

$$
\pi_{2}=\rho \lambda n_{2}-c_{2}=\rho \lambda \tau h-c_{2}
$$

Going backwards, we derive the value of waiting and the anticipatory value for the brand owner. As before, the anticipatory value is independent of the existence of squatting. Thus, it is still given by equation (2). Since an opposition will be filed, our calculations to obtain the value of waiting are considerably simplified. The brand owner will get $\pi_{\mathrm{o}}$ when the squatter is available and $h-c_{1}$ when he is not available. Therefore the value of waiting becomes

$$
\hat{w}_{1}=\mu \xi \pi_{\mathrm{o}}+\mu(1-\xi)\left(h-c_{1}\right) .
$$

Recalling that $w_{1}^{*}$ is the value of waiting without an opposition stage, it follows that:

$$
\hat{w}_{1}=w_{1}^{*}+\mu \xi\left(\kappa^{*}-\kappa\right) \geq w_{1}^{*}
$$

since $\kappa^{*} \geq \kappa$. Hence, the net value of waiting is always (weakly) higher in the presence of an opposition stage. This result should not be too surprising since the brand owner has always the option of not filing an opposition. It is then straightforward to find cut-off values for $c_{1}^{*}$ and $c_{2}^{*}$ such that a squatting active equilibrium exists despite the possibility of an opposition.

\section{A.4 Proof of Proposition 3}

Proof. It follows directly from our previous definitions and the expressions for $c_{i}^{*}$ for $i=1,2$. 


\section{A.5 Proof of Proposition 4}

Proof. Note that $c_{2}^{*}$ is a constant function of $\xi$. Hence it does not change when $\xi$ changes. Since $\frac{\partial c_{1}^{*}}{\partial \xi}>0$ we have the result.

\section{A.6 Proof of Proposition 5}

Proof. Note that $c_{2}^{*}$ is a constant function of $\mu$. Hence it does not change when $\mu$ changes. Since $\frac{\partial c_{1}^{*}}{\partial \mu}>0$ we have the result.

\section{A.7 Proof of Proposition 6}

Proof. Simple calculations yield:

$$
\frac{\partial c_{2}^{*}}{\partial \lambda}=\frac{c_{2}^{*}}{\lambda}>0, \quad \frac{\partial c_{1}^{*}}{\partial \lambda}=\frac{c_{1}^{*}(1-\mu)}{\lambda[\mu \lambda \xi+(1-\mu)]}>0
$$

Thus as $\frac{\partial c_{1}^{*}}{\partial \lambda}>0$, the pre-emptive equilibrium is increasing in $\lambda$. To demonstrate that the squatting active equilibrium is increasing in $\lambda$, it suffices to show that

$$
\frac{\partial c_{2}^{*}}{\partial \lambda}-\frac{\partial c_{1}^{*}}{\partial \lambda}>0
$$

Using the preceeding expressions we have:

$$
\frac{\partial c_{2}^{*}}{\partial \lambda}-\frac{\partial c_{1}^{*}}{\partial \lambda}=\frac{\lambda^{-1}}{\mu \lambda \xi+(1-\mu)}\left(c_{2}^{*} \mu \lambda \xi+(1-\mu)\left(c_{2}^{*}-c_{1}^{*}\right)\right)>0,
$$

since $c_{2}^{*} \geq c_{1}^{*}$.

\section{A.8 Proof of Proposition 7}

Proof. First note that:

$$
d \mu \cdot h+\mu \cdot d h=0 \Rightarrow d h=-\frac{h}{\mu} \cdot d \mu .
$$

Notice now that:

$$
d c_{2}^{*}=\lambda \tau d h=-\frac{\lambda \tau h}{\mu} \cdot d \mu>0,
$$

since $d \mu<0$. Proceeding along similar lines, after some simple mathematical manipulations, we have:

$$
d c_{1}^{*}=[(1-\lambda \xi) \mu \lambda \xi \tau h] \cdot d \mu<0,
$$

since $d \mu<0$. 


\section{A.9 Proof of Proposition 8}

Proof. Note first that:

$$
\frac{\partial c_{1}^{*}}{\partial h}=\left(\frac{\partial c_{1}^{*}}{\partial h}\right)_{\mu \text { fixed }}+\frac{\partial c_{1}^{*}}{\partial \mu} \frac{\mu}{\partial h}
$$

After simple calculations:

$$
\left(\frac{\partial c_{1}^{*}}{\partial h}\right)_{\mu \text { fixed }}=\frac{c_{1}^{*}}{h} ; \quad \frac{\partial c_{1}^{*}}{\partial \mu} \frac{\partial \mu}{\partial h}=\frac{\gamma c_{1}^{*}}{\mu[\mu \lambda \xi+(1-\mu)]},
$$

and since:

$$
\frac{\partial c_{2}^{*}}{\partial h}=\frac{c_{2}^{*}}{h}
$$

we have that:

$$
\frac{\partial c_{2}^{*}}{\partial h}-\frac{\partial c_{1}^{*}}{\partial h}=\frac{\left(c_{2}^{*}-c_{1}^{*}\right)}{h}-\frac{\gamma c_{1}^{*}}{\mu[\mu \lambda \xi+(1-\mu)]}
$$

Finally, note that:

$$
\frac{\partial c_{2}^{*}}{\partial h}-\frac{\partial c_{1}^{*}}{\partial h} \geq 0 \Longleftrightarrow \gamma \geq \gamma^{*}=\mu(\mu \lambda \xi+(1-\mu))\left(\frac{c_{2}^{*}}{c_{1}^{*}}-1\right)>0
$$

\section{B Appendix: 'Squatter algorithm'}

To identify squatters in the trademark register, we define ten criteria. The first criterion refers to the type of applicant:

- Applicant type. Our data allow us to distinguish between four applicant types: (i) individuals, (ii) companies, (iii) universities and research institutions, and (iv) government entities. We discard (iii) and (iv) from the set of potential trademark squatters assuming that such entities will not engage in squatting behavior.

The following three criteria require action on the side of third parties (opposition and cancellation) or the trademark office (rejection):

- Opposition ratio. Depending on the trademark that the squatter attempts to register, the company that is marketing the corresponding product or that is operating under the relevant trading name may learn about the filing of the trademark. This may happen if the company actively monitors trademark publications in a given market. Alternatively, legal counsels may monitor trademark publications and pro-actively approach the company concerned advising the company to file 
an opposition. This means that squatters could experience a relatively larger number of oppositions to their trademark applications. As shown in Section A.3 above, squatting is still an equilibrium even when brand owners can oppose their filings. We compute the opposition ratio as the share of all applications by a given applicant that was subject to opposition (regardless of whether the opposition was successful or not). We keep only applicants that are in the top 25th percentile of the opposition ratio distribution.

- Cancellation ratio. As described in Section 3.2, if a trademark passes the relative and absolute grounds examination and has been registered, third parties still have the possibility to have it cancelled. If a squatter uses a trademark to holdup a brand owner, the brand owner may attempt to cancel the trademark instead of paying off the squatter. This means that we should see relatively many cancellation proceedings associated with trademarks held by squatters. We compute the ratio as the share of trademark applications by a given applicant for which cancellation proceedings have been initiated (regardless of the outcome).

- Rejected applications. If a trademark office carries out a relative grounds examination, an examiner may reject a trademark application if he recognizes the trademark as a well-known brand. Since squatters are likely to target such wellknown brands because of their large $h$, even when their chances of success are low, squatters may have a relatively larger number of rejected applications in their portfolio of trademark applications. We compute the rejection ratio as the share of all applications by a given applicant that were rejected. We keep only applicants that are in the top 25th percentile of the rejection ratio distribution.

The following six criteria concern the filing behavior of squatters:

- Simultaneous filings. We have the precise filing date of trademarks. This allows us to identify applicants that file a large number of trademarks at the same time. If companies constantly develop new products and services, one would not expect to see a highly concentrated filing behavior, but rather a constant stream of filings. Squatters, in contrast, may file a large number of applications in intervals as filing only requires the identification of a (potentially) valuable existing brand and not the production and marketing of the corresponding product and service. In addition bundling applications may allow squatters to reduce administrative expenses associated with applications, i.e. distribute fixed costs over a larger number of applications. While this behavior in itself may not point to squatting behavior, it could be a useful identifier in combination with the other criteria. We compute the ratio of simultaneous filings as the share of all applications by 
a given applicant that were filed on a single day within a given year. We keep only applicants that are in the top 25th percentile of the resulting distribution.

- Diversity of Nice classes. The principal criteria for squatters in selecting trademarks should be the combination of the likelihood of obtaining a registered trademark and its potential market value. In principle, this should be uncorrelated with the Nice class of a given trademark. Companies, in contrast, commonly pursue relatively narrow lines of business (although this can clearly vary by industry and company size), which implies that their trademark filings should be more concentrated in fewer Nice classes. This means that we might be able to identify squatters by looking at the diversity of Nice classes in trademark filings. However, squatters may also specialize, for example in fashion labels, in which case this criterion has less identifying power if applied in isolation. We restrict this criterion to applicants with at least three filings. We compute the inverse of a normalized Herfindahl concentration index and keep only applicants that are in the top 25th percentile of the resulting distribution.

- Priority filings. Squatters - especially those active in middle income economies such as Chile - are very unlikely to operate internationally and to claim priority on a previous trademark filing in another trademark office. Companies that market products in various countries are much more likely to rely on priority rights to file trademark applications in multiple jurisdictions. As such, according to this criterion, we identify squatters as applicants without priority foreign filings.

- Trademark type. In Chile, the trademark system distinguishes between different uses of trademarks - notably products, services, slogans, and industrial as well as commercial establishments. Applicants that have trademarks in their portfolio that protect industrial as well as commercial establishments are most likely to pursue some productive activity themselves. Accordingly, this criterion defines squatters as those applicants that do not have filings indicating the protection of industrial or commercial establishments.

- Product vs. services. Squatters are likely to focus on trademarks on products rather than services, for example if they target famous fashion labels. We identify trademarks on products by Nice classes (Classes 1-34).

- Valuable brands. As explained in Section 2, trademark squatters target brands with relatively high brand recognition $h$ as this increases the hold-up value of squatting. We do the following to exploit this characteristic for the identification 
of squatters. We use the Interbrand list of the 100 most famous brands for each year between 2000 and 2011 as a starting point to identify squatters. We search the Chilean trademark register for these brands. Any applicant that is not the legitimate brand owner - which we verify manually - is considered a squatter. Propositions 5 and 8 , however, show that squatters are less likely to succeed squatting such highly successful brands. It turns out that squatters nevertheless have a few such (failed) applications in their portfolio. In order to capture squatters that pursue the registration of for example risky brands (Proposition 7) or brands of potentially some more intermediate value (Proposition 8), in a second step, we obtain all other trademarks applied for by these squatters. In a third step, we look for all applicants that have any of the trademarks found in step two in their portfolio. In each step, we clean the output manually for false positives. 